\title{
Prioritization in visual search: Visual marking is not dependent on a mnemonic search
}

\author{
CHRISTIAN N. L. OLIVERS, GLYN W. HUMPHREYS, DIETMAR HEINKE, and ADAM C. G. COOPER \\ University of Birmingham, Birmingham, England
}

\begin{abstract}
Visual marking (VM) refers to our ability to completely exclude old items from search when new stimuli are presented in our visual field. We examined whether this ability reflects an attentional scan of the old items, possibly allowing observers to apply inhibition of return or maintain a memory representation of already seen locations. In four experiments, we compared performance in two search conditions. In the double-search (DS) condition, we required participants to pay attention to a first set of items by having them search for a target within the set. Subsequently, they had to search a second set while the old items remained in the field. In the VM condition, the participants expected the target only to be in the second (new) set. Selection of new items in the DS condition was relatively poor and was always worse than would be expected if only the new stimuli had been searched. In contrast, selection of the new items in the VM condition was good and was equal to what would be expected if there had been an exclusive search of the new stimuli. These results were not altered when differences in Set 1 difficulty, task switching, and response generation were controlled for. We conclude that the mechanism of VM is distinct from mnemonic and/or serial inhibition-of-return processes as involved in search, although we also discuss possible links to more global and flexible inhibition-of-return processes not necessarily related to search.
\end{abstract}

The present paper addresses the prioritization of new over old objects. In many situations, it is advantageous to prioritize new objects, if only because it leads to an updated representation of our environment (Yantis, 1998). Often, older objects quickly lose their relevance completely. For instance, when we are eagerly waiting for the bus to emerge from the distance, an approaching lorry may cause an initial stir but is then rapidly ignored. In other situations, the new object may be less relevant. For instance, when the bus has finally appeared, new lorries emerging behind it do not need prioritization. Hence, to be maximally adaptive, the visual system must be able to distinguish already seen objects from new objects and to exert considerable top-down control over the prioritization of one type over the other.

\section{Visual Marking}

One situation in which old objects appear to be almost perfectly avoided is the preview paradigm developed by Watson and Humphreys (1997, 1998, 2000; Watson, 2001; see also Olivers, Watson, \& Humphreys, 1999; Theeuwes, Kramer, \& Atchley, 1998). Watson and Humphreys (1997) used a standard conjunction search task, in which participants had to decide whether a blue $\mathrm{H}$ target was present among blue $\mathrm{A}$ and green $\mathrm{H}$ distractors. In ac-

Grants from the Medical Research Council (U.K.) and the European Union supported this work. We thank Kia Nobre, Arni Kristjansson, Todd Horowitz, and Kim Shapiro for useful comments on an earlier version of this paper. Correspondence concerning this article should be addressed to G. W. Humphreys, Behavioural Brain Sciences, School of Psychology, University of Birmingham, Birmingham B15 2TT, England (e-mail: g.w.humphreys@bham.ac.uk). cordance with many previous conjunction results, they found relatively steep slopes for the search functions (i.e., strong effects of the number of items [the display size] on response times [RTs]). In a second, critical condition (the preview condition), one set of distractors (the green Hs) was presented first, followed after 1,000 $\mathrm{msec}$ by the second set of items (blue A distractors and possibly a blue $\mathrm{H}$ target: see also Kahneman, Treisman, \& Burkell, 1983). The first items remained when the second set appeared, so that the final display was identical to that in the conjunction condition. Despite this, the participants searched much more efficiently in the preview condition, relative to the standard conjunction baseline: The slopes of the search functions were halved, indicating that all the old items could be excluded from search.

It is likely that part of this benefit in the preview condition is due to automatic attentional capture by the abrupt new onsets (e.g., Yantis \& Jonides, 1984). However, additional experiments indicate that this is not the entire story. For instance, giving participants a secondary (shadowing) task during the initial stage, when only the first half of distractors are present, results in less efficient search through the subsequently presented new display (Olivers \& Humphreys, 2002b; Watson \& Humphreys, 1997). Apparently, some attentional resources are required in order to ignore the old items and/or prioritize the new. Second, Watson and Humphreys (2000) also showed that observers have considerable top-down control over the prioritization of new over old, with old items being inhibited when new stimuli were prioritized. In their experiment, on the majority of trials, the participants carried out a search in the standard preview condi- 
tion. However, on a minority of trials, the participants had to detect a probe dot, rather than search for the target. There was a large drop in the efficiency of detecting probes at the locations of the old items, relative to those of the new items. This decrease was much stronger for old items in the preview conditions than for the same stimuli when they were presented simultaneously with all the other distractors in a conjunction baseline. Interestingly, when the visual conditions stayed the same but the task changed so that probes had to be detected on every trial, the large decrement for probe detection on the old items was eliminated. There appeared to be prioritization of new items only when the task required so (see also Olivers \& Humphreys, 2002b, for similar results).

To account for these and other findings, Watson and Humphreys (e.g., 1997) proposed a mechanism of visual marking (VM). VM involves the inhibitory tagging of irrelevant visual objects, so that relevant future objects can be selected efficiently. More specifically, Watson and Humphreys suggested that the locations of old distractors are suppressed so that new locations gain priority in selection. Watson and Humphreys further proposed that VM is a top-down, limited capacity mechanism, constrained by the task goals and the available attentional resources. Hence, marking is less efficient when a dual task is introduced during the preview interval and is more pronounced when the task requires new items to be prioritized.

An important question is how VM is implemented. Watson and Humphreys $(1997,1998)$ suggested that the inhibition originates from one of the goal states of the observer-namely, the goal to ignore the old items. This goal state results in the set-up of an inhibitory template specifying the to-be-ignored information. Any visual object complying with this template will thus be ignored. Together with Watson and Humphreys (1997), we envisage that this top-down mechanism of suppression operates in parallel across the visual field, in that all items complying with the inhibitory attentional set will be suppressed simultaneously. However, another possibility is that the inhibition is applied in a more serial manner. Observers may choose to deliberately attend to the old items on an item-by-item basis, either remembering or inhibiting the individual positions, so they can avoid the old items when searching the new. If so, VM would very much resemble processes thought by some to occur during normal visual search, such as serially applied inhibition of return.

\section{Mnemonic Search}

Some researchers have argued that the visual system needs to distinguish old from new even in static visual search scenes (i.e., ones in which all objects appear simultaneously). The idea is that, when searching for a target object, the observer somehow needs to memorize which objects (or locations) have already been inspected. Klein (1988) argued that the visual system might ac- complish this by assigning inhibitory tags to previously attended locations - a mechanism known as inhibition of return (Maylor \& Hockey, 1985; Posner \& Cohen, 1984). Consistent with this idea, Klein (1988) found that probe dots presented at searched locations were more difficult to detect than probe dots at other locations. Importantly, Klein further argued that such inhibitory tagging should be limited to inefficient serial search, because inhibition of return, by definition, first requires attention to be focused on the to-be-inhibited locations or objects before they can be inhibited. This was supported by evidence that inhibitory effects did not occur on responses to probes presented in easy parallel search displays (see Müller \& von Muhlenen, 2000, and Takeda \& Yagi, 2000, for recent replications).

Recent evidence by Kristjansson (2000) also points toward already checked objects' being tagged as such. Kristjansson, using a method pioneered by Horowitz and Wolfe (1998; see below), found that there was an RT cost when search targets appeared in positions previously occupied by distractors, relative to when target and distractors did not exchange positions. Kristjansson therefore argued for a strong role for memory of old locations in visual search. Treisman, Vieira, and Hayes (1992) also concluded that visual search involves some form of memory, but, in accordance with Klein's (1988) findings, only when search is inefficient. Using a conjunction search task in which the target appeared in one location more often than in other locations, they found large benefits when the target appeared in its usual position and costs when it did not. However, no such location effects were found in a single-feature search task. Treisman et al. concluded that, in contrast to single-feature search, conjunction search requires that selective attention be directed to the locations of the items. At the same time, this directed attention allows locations to be remembered and used in subsequent trials (see also Logan, Taylor, \& Etherton, 1999). Recently, Chun and Jiang (1998) have extended these findings by showing benefits when complete prior search displays were re-presented (i.e., when not only the targets, but also the distractors were repeated). These benefits occurred even after a single repetition and even though the participant was unaware of the repetition. This indicates that visual search leaves at least some implicit memory that can guide attention in the future. Perhaps the strongest view on this is represented by Logan's $(1988,1990$; Logan et al., 1999) instance theory, which states that "encoding into long-term memory is a necessary consequence of attention. Whatever is attended is encoded into memory" (Logan et al., 1999, p. 166).

This opens the interesting possibility that memory in visual search and VM involve the same mechanisms. For instance, participants may adopt a strategy of "searching" the old set (even though they know the target is not there), in order to memorize and avoid those occupied locations in the future. VM may also be achieved by merely 
paying attention to the old set, resulting in inhibition of return. Such an account could also explain the fact that VM is disrupted by an attention-demanding secondary task, since such a task may prevent observers from applying their attentional scan to the old items. The present paper provides a test for the mnemonic search account.

Before we present our experiments, it is worth noting that the notion that memory plays a role in search has recently been challenged, resulting in an interesting controversy (Gibson, Li, Skow, Brown, \& Cooke, 2000; Gilchrist \& Harvey, 2000; Horowitz \& Thornton, 2000; Horowitz \& Wolfe, 1998, 2001; Kristjansson, 2000). Although our results will have some relevance to the issue, the controversy is not central to the present paper. Our paper is built on the premise that memory in visual search may exist and could thus play a role in the preview effects presently associated with VM. If it turns out that such memory does not exist in search, this will only strengthen the conclusion we arrive at here-namely, that the preview benefits associated with VM cannot be due to mnemonic search.

As a second note, we will use the term mnemonic search for any deprioritization processes thought to operate in effortful (serial) visual search. This includes the serial inhibition-of-return processes proposed by Klein (1988), Müller and von Muhlenen (2000), and Takeda and Yagi (2000). Note again that these researchers all found evidence for inhibition for effortful search (demanding focused attention), but not for easy search (probably demanding only distributed attention). In this respect, we see inhibition of return as a rather low-level orienting mechanism (possibly linked to the oculomotor system; Klein \& Taylor, 1994), aiding the attentional system in orienting away from already inspected locations or objects. By this definition, inhibition of return is highly spatial: Attention must have been drawn toward or focused on a specific location in the visual field first, before it is tagged for inhibition (hence, effects occur only with what are thought of as serial searches). However, this may not be the only definition of inhibition of return, an issue we will return to later.

\section{Overview of the Experiments}

In the present study, we report four visual search experiments in which the visual system's ability to ignore already searched items is investigated and compare this ability to a typical preview situation in which old items need not be searched. For this purpose, we developed what we called the double-search (DS) task. In the DS task, participants first conduct a standard visual search. After a set time period (Experiment 1), or after the participants have responded to the first search set (Experiments 2, 3, and 4), a second set of items is added to the items already there (which stay present in the display), and the participants are required to search this second set too. The efficiency of search through the second set (i.e., the search slope) then serves as a measure of how effec- tively the participants have ignored the old, already searched items belonging to the first set. If the participants can completely ignore the already searched set, search through the second set should be as efficient as when the first set is absent. However, if, when searching the second set, observers return to old items and include them in their search, search slopes should be greater than when the first set is absent. This way we can determine whether memory for old, already searched items is perfect or not.

We compared performance in the DS condition to a VM condition in which participants did not need to search the first set, because the target either always or most likely appeared in the second set. This allowed us to answer two important questions. First, are participants able to avoid items they have just searched? Second, in the standard VM case, is anything more involved in the preview effect than an attentional scan of the old items? If the preview effect is due to participants' serially attending the old set, performance in both conditions should be identical. On the other hand, if the preview effect is caused by the active top-down inhibition of old items and a mnemonic search is not sufficient, performance in the DS condition ought to suffer, relative to the VM condition.

\section{EXPERIMENT 1 Varying Target Probability}

In all the conditions, the total set of items was presented in two stages, one set appearing 1,000 msec after the other. In different blocks, we varied which half the participants expected the target to be in, as is illustrated in Figure 1. In the DS condition, the target was in the first set of items on the majority of trials ( $84 \%$ validity). However, on a minority of trials $(16 \%)$, the target came only with the second set of items. The participants were informed about this by a high pitch cue, which sounded just before the second set appeared. We assumed that, since this last cue would come only with the second set, the participants would have searched the first set of distractors, switching to the second set only after they had exhaustively scanned all the items or after they had heard the second auditory cue telling them that they were searching the wrong set.

In the VM condition, the situation was reversed, since the target was most likely to appear in the second set ( $84 \%$ validity). We assumed there would be less incentive to search the first set in this condition, relative to the DS condition. On $16 \%$ of the VM trials, however, the first set actually contained a target. On these trials, the observers were notified of the target's temporal occurrence by a low pitch tone just before the second set appeared.

We expected an overall effect of validity. RTs are likely to show an overall increase when observers are set for the wrong set of items, particularly when the second set is cued and the target appears in the initial set (i.e., in the 


\section{A. Double Search Condition (DS)}

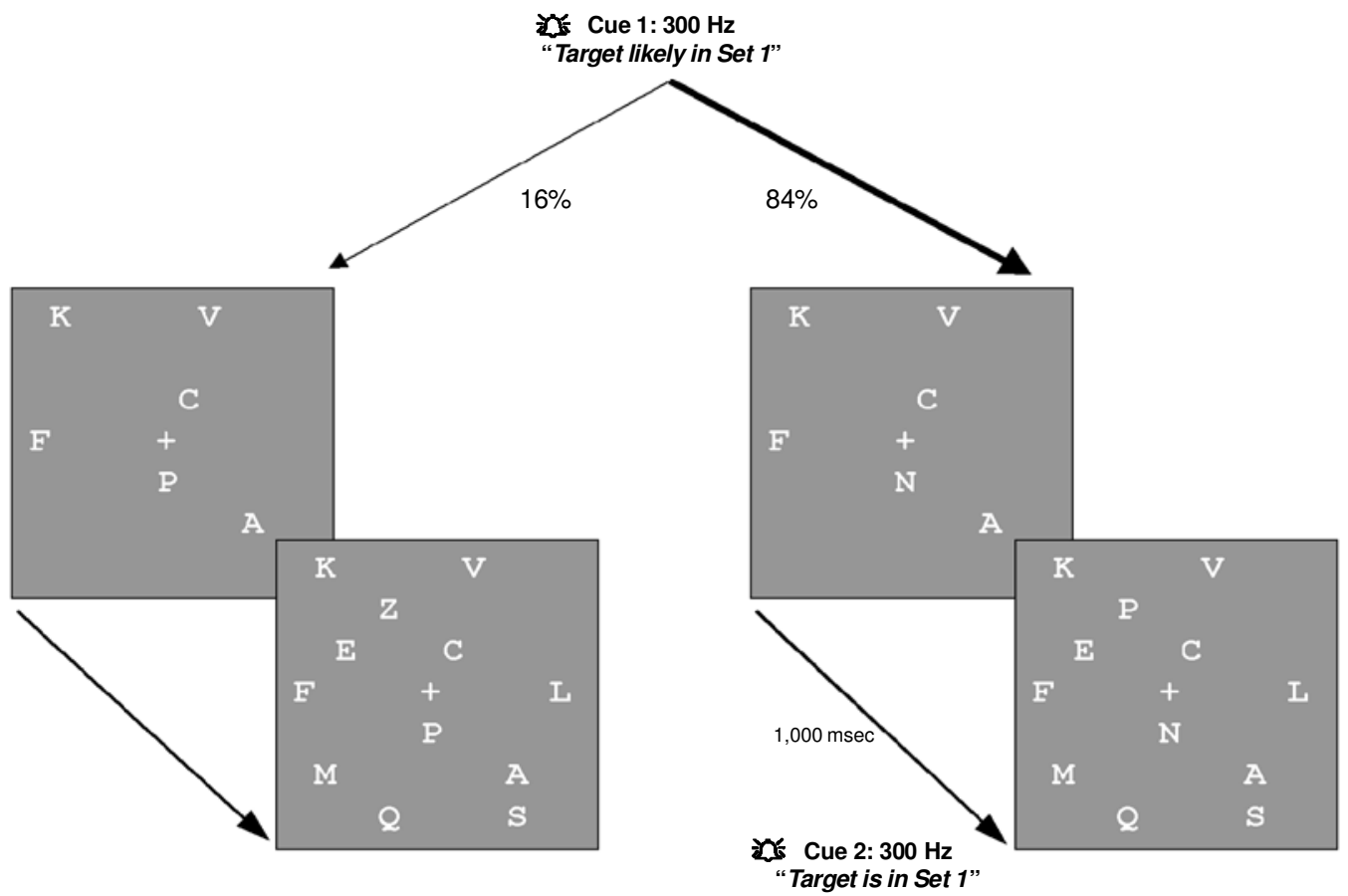

\section{B. Visual Marking condition (VM)}

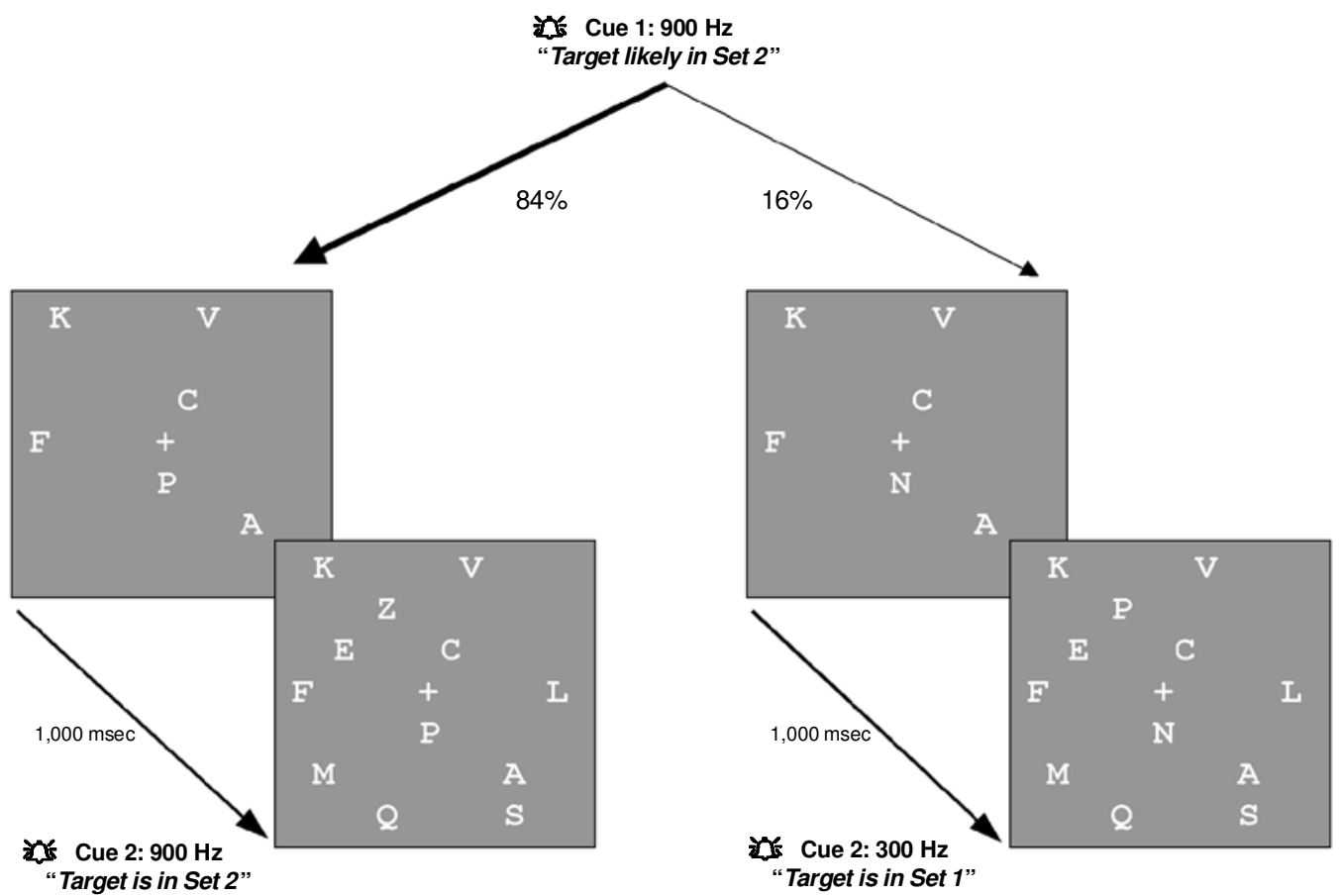

Figure 1. Example conditions from Experiment 1. See the main text for explanations.

VM condition; see Coull \& Nobre, 1998, for evidence). A second prediction is that, if, in the DS condition, search through the first set has kept track of the old items and has effectively deprioritized them, the second set should be selected efficiently. In other words, if preview effects previously demonstrated are due to an attentional, search-like strategy, search for targets in the second set would be expected to be at least as good in the DS con- 
dition as in the VM condition. In the extreme case, performance in the VM condition may be expected to be worse, since participants would not expect a target in the first set and might, therefore, not always undertake an attentional scan of the first set. If, however, different or additional processes generate the preview effect, performance may be more efficient in the VM condition than in the DS condition.

Baselines for measuring search efficiency to targets in Set 2 can be provided by search slopes to targets in Set 1 , particularly in the DS condition. In that condition, participants should set out to find the target in Set 1. The slope of the search function should thus indicate the state of search estimated when half of the full set of distractors is present. If observers are able to ignore Set 1 distractors, when the target is in Set 2, search through Set 2 should be as efficient as search for a target in Set 1 in the DS baseline, since exactly half the total number of items are present in both sets. If the slope for Set 2 targets is increased, however, this would indicate that Set 1 distractors are being included in the search set.

\section{Method}

Participants. Twelve undergraduates from the University of Birmingham participated for course credit or a small payment. There was 1 male participant, and all were right-handed. Average age was 19.3 years (range, 18-23). Three participants were replaced because they made too many errors in one of the cells $(>25 \%)$. One of these made too many errors in Set 2 search in the VM condition (in which the target was expected in Set 2). The other 2 made too many errors on Set 2 search in the DS condition (in which the target was expected in Set 1).

Stimuli and Apparatus. White letters (16-point Courier font) measuring roughly $0.4^{\circ} \times 0.4^{\circ}$ were randomly positioned in an $8 \times$ 8 virtual grid on a light-gray square background $\left(10^{\circ} \times 10^{\circ}\right)$. Within each grid position, the letters were randomly displaced between $0^{\circ}$ and $0.15^{\circ}$ in any direction. The stimuli were generated by a PC and presented on a 15 -in. SVGA screen in $640 \times 480$ resolution mode, viewed from about $85 \mathrm{~cm}$. The letters were drawn randomly from the entire alphabet, excluding the targets, with one of them being replaced by one of the target letters ( $\mathrm{N}$ or $\mathrm{Z}$ ). The total display size was either 12 or 20 , with 6 and 10, respectively, in the first set and another 6 or 10 in the second set of items. Each set was accompanied by an auditory cue (either a $300-\mathrm{Hz}$ low-pitch tone or a $900-\mathrm{Hz}$ high-pitch tone), presented $50 \mathrm{msec}$ before the respective set appeared and lasting for $50 \mathrm{msec}$.

Design and Procedure. Each trial started with a fixation cross $(500 \mathrm{msec})$, followed by one set of search items ( 6 or 10 , depending on the display size). After $1,000 \mathrm{msec}$, a second set was added to the first (containing another 6 or 10 items), unless the participant had already responded to the first set. Both sets remained in the field until the response or for a maximum period of $10 \mathrm{sec}$. Just before the start of each trial, an auditory cue indicated the set that would most likely contain the target. This cue was only a reminder, since the likelihood was already determined by the particular block. Just before the second set appeared, the participant heard a second auditory cue, now indicating the definite target set. There were two main conditions, which were presented in separate blocks. In the DS condition, the first tone (low pitch, $300 \mathrm{~Hz}$ ) always cued the first set. On valid trials $(84 \%)$, the second cue was another lowpitch tone, confirming the first cue. On invalid trials (16\%), the cue changed into a high-pitch $(900-\mathrm{Hz})$ tone, indicating that the second set contained the target. In the VM condition, the situation was reversed: The participants were cued toward the second set by a high- pitch tone, which was valid on $84 \%$ of the trials. On valid trials, the second tone was the same pitch as the first; on invalid trials, it changed to a low-pitch tone. The participants were informed of the cue-target relationships, and they were instructed to press $\mathrm{N}$ or $\mathrm{Z}$ on the keyboard as soon as they saw the target, regardless of which set the target appeared in or which set had been cued. Each trial ended with a blank screen for $750 \mathrm{msec}$.

Search RTs were measured from the onset of the set containing the target. At the end of the experiment, the participants had completed search through four sets: (1) the cued Set 1 in the DS condition, (2) the invalidly cued Set 1 in the VM condition, (3) the invalidly cued Set 2 in the DS condition, and (4) the validly cued Set 2 in the VM condition. Feedback was provided by a medium-pitch tone on incorrect trials only. Each participant completed three DS blocks and three VM blocks of 100 trials each, with the order counterbalanced across participants. The first block of each condition was regarded as practice and was not included in the analysis. The participants were allowed to move their eyes freely.

\section{Results}

Error percentages are shown in Table 1. The overall error rate was low (2.5\%). We analyzed the error slopes to see whether there were any speed-accuracy tradeoffs. Table 1 suggests an interaction between Set 2 in the DS condition (where there was a decrease in errors with display size) and Set 2 in the VM condition (where there was an increase in errors). However, this interaction failed to reach significance $\left[F(1,11)=2.48, M S_{\mathrm{e}}=5.67\right.$, $p=.14]$. It is not inconceivable that the participants were somewhat more careful for display size 20 in what turned out to be a very difficult DS condition (see below), but any effect was only minor and was not reliable. The following analyses focused on RTs. The search functions for the targets in Sets 1 and 2 in the DS and VM conditions are given in Figure 2. The slopes of the search functions were $47 \mathrm{msec} / \mathrm{item}$ for Set 1, DS; $48 \mathrm{msec} / \mathrm{item}$ for Set 1, VM; $90 \mathrm{msec} /$ item for Set 2, DS; and $53 \mathrm{msec} /$ item for Set 2, VM. These slope values were based on the total display sizes (12 and 20), although half this number appeared in both Set 1 and Set 2 . This was done in order to provide an estimate of the number of items searched once the second set had appeared. If only Set 2 items were searched, the slope should be half that if all the items were searched and equal to that in the estimated Set 1 condition, when the participants actually searched only half the total number of items present (see Watson \& Humphreys, 1997).

A recursive outlier elimination procedure with modified criterion, as recommended by Van Selst and Jolicœur (1994), eliminated 3.7\% of the correct RTs. The remaining correct RTs were entered in an analysis of variance

Table 1

Error Percentages for Experiment 1

\begin{tabular}{clll}
\hline \multirow{2}{*}{ Condition } & Validity & \multicolumn{2}{c}{ Display Size } \\
\cline { 3 - 4 } & Set 1 valid & 3.0 & 20 \\
\hline Double search & Set 2 invalid & 3.1 & 3.2 \\
& Set 1 invalid & 0.0 & 2.6 \\
Visual marking & Set 2 valid & 2.4 & 3.9 \\
\hline
\end{tabular}




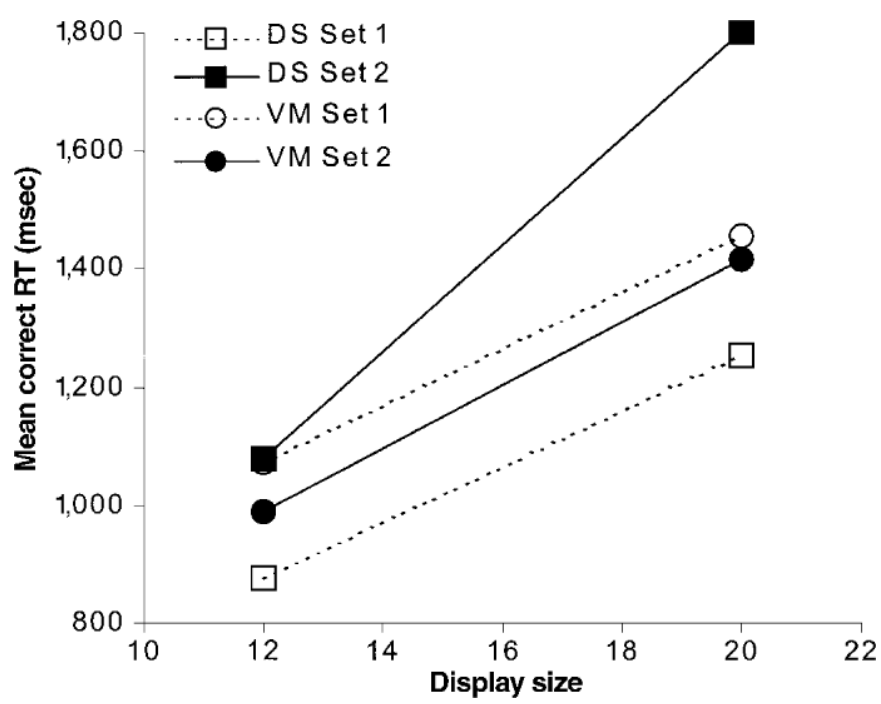

Figure 2. Mean response times (RTs) in Experiment 1. DS, double search; VM, visual marking.

(ANOVA), with block (Block 1, Block 2), target set (Set 1, Set 2), validity (valid, invalid), and display size $(12,20)$ as factors. Overall, search was rather inefficient, with slopes starting at $47 \mathrm{msec} /$ item for Set 1 items in the DS condition. Even for this condition, the slope was significantly different from zero [display size, $F(1,11)=$ $\left.110.6, M S_{\mathrm{e}}=98,484, p<.001\right]$, suggesting that attention had to be focused on each letter until the target was found. Search through the first set was generally quicker than that through the second set of items [target set, $\left.F(1,11)=9.7, M S_{\mathrm{e}}=122,680, p=.01\right]$, and validly cued trials were faster than invalidly cued trials [validity, $\left.F(1,11)=17.1, M S_{\mathrm{e}}=134,766, p<.01\right]$. Most important, there was a significant target set $\times$ validity $\times$ display size interaction $\left[F(1,11)=6.8, M S_{\mathrm{e}}=37,354, p<.05\right]$, reflecting a greater difference in search slopes between the targets in the invalid trials in Sets 1 and $2(48 \mathrm{msec} /$ item vs. $90 \mathrm{msec} /$ item $)$, relative to valid trials $(47 \mathrm{msec} / \mathrm{item}$ vs. $53 \mathrm{msec} /$ item). No other interactions approached significance. This three-way interaction is analyzed further below, by comparing performance with the RT data entered separately for Sets 1 and 2, as well as for valid and invalid trials

Set 1 targets. RTs were, on average, $200 \mathrm{msec}$ faster when the participants were validly cued (in the DS condition) than when they were invalidly cued [in the VM condition; validity, $\left.F(1,11)=5.3, M S_{\mathrm{e}}=91,184, p<.05\right]$. However, there was no validity $\times$ display size interaction, since search slopes were equal in these conditions (47 msec/item vs. $48 \mathrm{msec} /$ item, $p=.967$ ). Thus, although invalid cues did increase absolute RTs, search efficiency for the first set stayed the same.

Set 2 targets. RTs for invalid trials (now in the DS condition) were again slower than those for valid trials (in the VM condition), an effect of $238 \mathrm{msec}$, on average [validity, $F(1,11)=29.6, M S_{\mathrm{e}}=22,949, p<.001$ ]. However, now there was a difference between the search slopes, with RTs for the Set 2 targets being slower in the DS condition than in the VM condition $[90 \mathrm{msec} / \mathrm{item}$ vs. $53 \mathrm{msec} /$ item, respectively; target set $\times$ display size, $\left.F(1,11)=6.7, M S_{\mathrm{e}}=38,572, p<.05\right]$. Ten of the 12 participants showed this effect.

Valid trials. RTs in the DS condition (to Set 1 targets) were faster overall than RTs in the VM condition [to Set 2 targets; target set, $F(1,11)=11.2, M S_{\mathrm{e}}=20,371$, $p<.01]$. However, this was an intercept effect. Importantly, the target set $\times$ display size interaction failed to reach significance. There was no difference in search slopes ( $48 \mathrm{msec} /$ item for the first set, DS, vs. $53 \mathrm{msec} /$ item for the second set, VM, $p=.578$ ).

Invalid trials. There was a trend for RTs in the VM condition (to Set 1 targets) to be faster than RTs in the DS condition (to Set 2 targets; $p=.067$ ). More important, however, there was a significant target set $\times$ display size interaction $\left[F(1,11)=5.0, M S_{\mathrm{e}}=69,097, p<.05\right]$. In contrast to valid trials, on invalid trials search rates were slower in the DS condition (to Set 2 targets) than in the VM condition (to Set 1 targets). Search through the second set of items was less efficient than that through the first set, since slopes measured $90 \mathrm{msec} / \mathrm{item}$ for the invalidly cued second half (the DS condition), but only $48 \mathrm{msec} /$ item for the invalidly cued first half (the VM condition).

\section{Discussion}

In all the conditions, search was relatively slow and was strongly affected by the number of items in the display, consistent with an attentionally demanding and inefficient search's taking place. This is important, since such an attentional scan should optimize memory for, or 
inhibition of return at, the old locations (Chun \& Jiang, 1998; Klein, 1988; Logan, 1988; Maylor \& Hockey, 1985; Müller \& von Muhlenen, 2000; Posner \& Cohen, 1984; Takeda \& Yagi, 2000).

The important question is how well the participants ignored the first set when Set 2 appeared. Search slopes in the VM condition were as fast as those to Set 1 targets in the DS condition (which served as our baseline). In other words, the old (Set 1) distractors had little effect in the VM condition. This result replicates the finding of Theeuwes et al. (1998), confirming that marking occurs even in a relatively difficult search task. In contrast, the Set 2 slopes in the DS condition were almost doubled. Indeed, there was no statistical difference between the slopes of these targets and the doubled slopes of Set 1 targets in the same condition $[t(11)=0.18, p=.862]$. This suggests that, in the DS condition, there was little to no memory for already searched items. Importantly, the clear contrast between search for Set 2 targets in the DS and VM conditions is consistent with the preview effect's being caused by a different process than that involved in attentionally demanding search.

However, there may be other reasons for why memory for old items was so limited in the DS condition. It may be that the participants were startled by the low-probability Set 2 trials in the DS condition, which may have led to a reset of the attentional system. In the VM condition, the participants were set to search the second batch of items and may have been much less startled. A second explanation is that, in the DS condition, old items were adequately tagged with inhibitory tags but that these tags had mostly decayed by the time search through the second set started. This might have been especially detrimental to the DS condition, because search through the second was likely to be overall delayed owing to the invalid temporal cue. Another possibility is that the participants simply may not have had enough time to search and memorize or inhibit Set 1 in the DS condition. One indication that this might be the case is that average search times for the larger display sizes in Set 1 of the DS condition are longer than the $1,000 \mathrm{msec}$ at which the second set appeared. Note, however, that in the VM condition there was apparently sufficient time to ignore the old items. Nevertheless, it is possible that, in both conditions, an inhibitory attentional scan is applied to the old items but that it is simply quicker in the VM condition (e.g., because the items do not need to be identified), allowing for more items to be inhibited within the 1,000 -msec preview period. The following experiments were designed to control for these alternatives.

A further interesting observation here is that the present pattern of data contravenes the results found when temporal cues are used in simple detection tasks (Coull $\&$ Nobre, 1998; Kingstone, 1992). There (as here), a cost in RTs to targets appearing in an unexpected time interval is observed. However, the cost is larger for targets presented early than for targets presented late but cued early. It is as if participants cued early can reset their temporal expectations when targets are late. In contrast, we found that costs on invalid trials were larger for targets presented late (in Set 2) when expected early (in Set 1), in the DS condition. It is therefore difficult to attribute performance in the DS condition to simple consequences of temporal expectancies.

A final point of interest lies in the Set 1 search conditions. RTs were slowed (by about $200 \mathrm{msec}$ ) in the VM Set 1 condition (when these targets unexpectedly appeared in the first set) relative to the DS Set 1 condition (when these targets were expected to appear in the first set). This effect could have been brought about by several factors-including an expectancy about the onset of target displays or the need to recover old (Set 1) items if they were subject to inhibition-and is therefore not surprising. What is surprising is that it was an effect on the intercept, rather than the slope, of the search functions. Apparently, once initiated, search of Set 1 items in the VM condition was as efficient as when search of the same items began at the start of a trial (in the DS condition). At present, we have no clear explanation for this effect. We suggest that observers are likely to maintain an attentional set for the target properties, and, although they expect these properties to emerge in the second set, they may inadvertently be guided toward the target when it appears in the first set (see, e.g., Folk, Remington, \& Johnston, 1992). Alternatively, the old items may form a strong coherent group on the basis of their common onset, and the visual system may have access to this group throughout the trial (cf. Takeda \& Kumada, 2002; see also the General Discussion section).

\section{EXPERIMENT 2}

\section{Second Set Follows Absent Response to First Set}

The main change between Experiments 1 and 2 was that, in Experiment 2, the second set of stimuli appeared only after the observers had searched the first set completely, as indicated by their own response. This was done in order to optimize the participants' preparation for the Set 2 items in the DS condition. The task was changed to a present/absent decision (was a target $\mathrm{H}$ present or not?), and Figure 3 shows the layout for a typical display. On the critical trials, the $\mathrm{H}$ was absent from Set 1 but present in Set 2. However, Set 2 was added only once the absent response had been made to Set 1 . Presumably, the observers responded absent following exhaustive search of Set 1 . Having done this, the participants should then not be surprised by the appearance of the Set 2 items, which are entirely predictable after an absent response to Set 1 . In addition, because the participants themselves determined how much time they needed for Set 1 , this procedure ensured that all of the Set 1 items could be subject to attention before Set 2 occurred.

One additional change was made. In Experiment 2A, we compared the DS condition to a full-set baseline condition, in which all the items (Set $1+$ Set 2) were presented simultaneously. If search in the DS condition 


\section{A Double-Search condition}

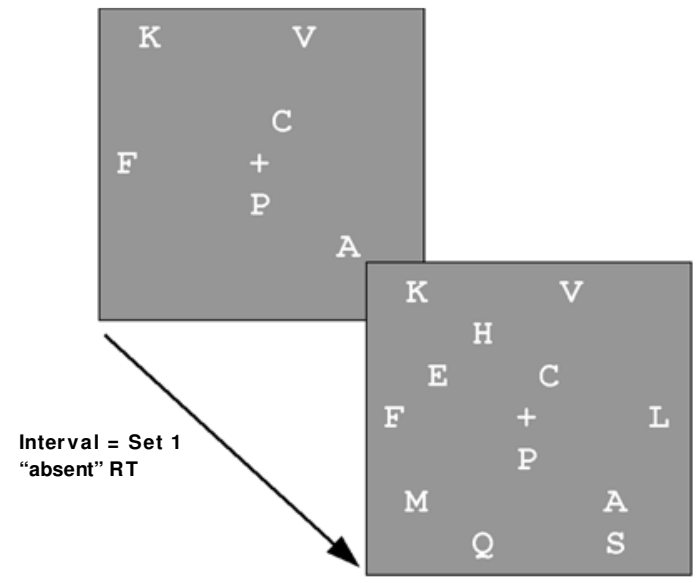

B Double-Search condition

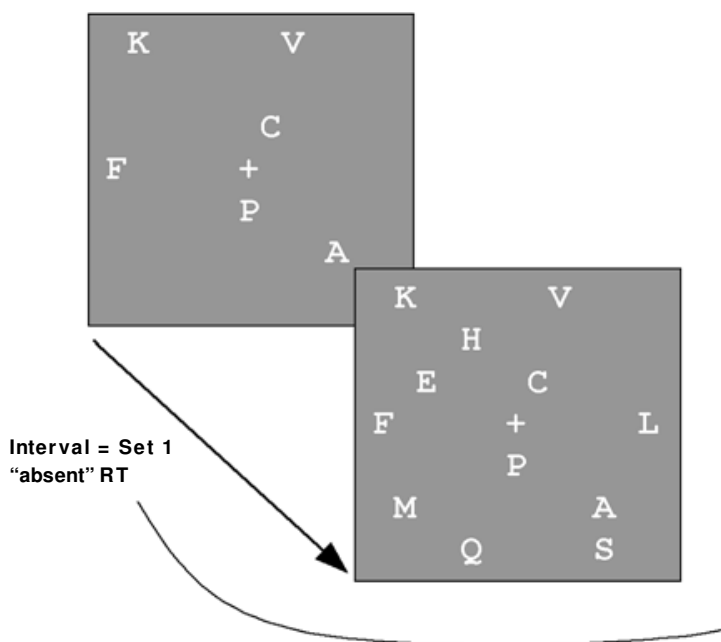

Full-Set condition

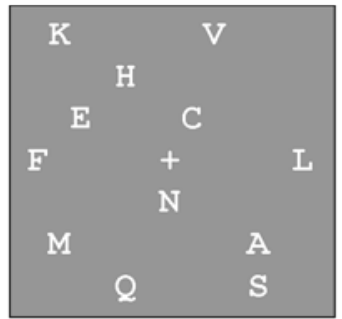

\section{Visual-Marking condition}

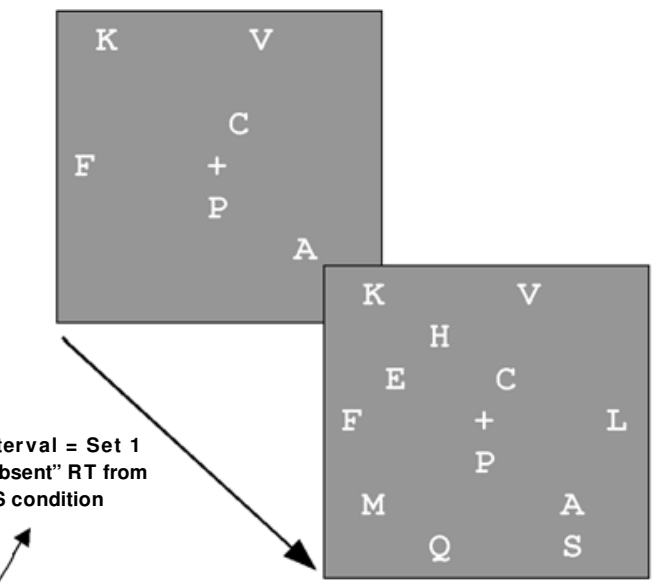

Figure 3. Typical examples from Experiment 2. In the double-search (DS) condition, the participants had to determine whether the target $(\mathrm{H})$ was in the first set, and contingent upon its absence (as here), whether it was in the second half (here present). In Experiment $2 \mathrm{~A}$ (panel A), performance was compared to a full-set condition, in which Sets 1 and 2 were presented simultaneously and the participants made a single absent/present response. In Experiment $2 B$, performance was compared to a visual-marking condition, in which the second set appeared automatically at controlled intervals. These intervals were determined by the participant's performance in previous DS blocks (see the main text).

starts all over again after Set 2 appears, performance should match that of the full-set baseline. However, if any old items are successfully ignored, the Set 2 slope should be less steep than the full-set slope. Subsequently, in Experiment 2B, we investigated whether a VM condition led to further improvements, relative to the DS condition. If so, we could again conclude that the preview effect must have been based on processes other than just memory for searched items. In the VM condition, no response was required to the Set 1 items, and Set 2 stimuli appeared automatically after a time interval that was exactly matched to an earlier interval from the DS condition, for that participant. We did this by saving the RTs to Set 1 of the DS in a list, which was subsequently used to determine the timing of the onset of Set 2 items in the VM condition (see the Method section and Figure 3). Since in both conditions, the time of appearance of Set 2 items was determined by the participant's speed of search through Set 1 items, serial search and VM had exactly equal opportunities of being implemented in time, even if the serial scan was slower in the DS condition than in the VM condition. Also, any decay of inhibitory tags should be equal for the time-matched conditions.

\section{Method}

Participants. Thirty-three undergraduates of the University of Birmingham ( 2 males, 2 left-handed) participated for course credit or money. The average age was 20.2 years (range 18-31). Eight par- 
ticipants were replaced because they made more than $25 \%$ errors in one of the cells (4 in the VM condition, 4 in the DS condition, mainly for the highest display size). Fourteen participants participated in Experiment 2A, 19 in Experiment 2B. ${ }^{1}$

Stimuli and Apparatus. Displays and equipment were the same as those in Experiment 1. However, the target was now a capital $\mathrm{H}$ instead of an $\mathrm{N}$ or a $\mathrm{Z}$.

Design and Procedure. In Experiment 2A, there were two main conditions (see Figure $3 \mathrm{~A}$ ). In the full set baseline condition, the fixation cross was followed by only one visual search display, consisting of 12 or 20 letters. On half the trials, the target $(\mathrm{H})$ replaced one of the distractors. The participants had to respond absent or present as quickly and accurately as they could, after which the trial ended. In the DS condition, the participants first searched one set of 6 or 10 items for the $\mathrm{H}$, which was present on $50 \%$ of the trials. In case of target presence, the trial ended with the response. However, when the participants responded absent correctly, another 6 or 10 items were added to the first set, again containing a target on $50 \%$ of the trials. The participants then had to determine as quickly as possible whether an $\mathrm{H}$ appeared among the newly arrived items. Search RTs were measured from the onset of the target. Thus, at the end of Experiment 2A, the participants had performed three search tasks: (1) search through the full set (full-set baseline), (2) search through Set 1 in the DS condition (Set 1 baseline), and (3) search through Set 2 in the DS condition after Set 1 had been searched.

The procedure in Experiment 2B was largely the same, except that now the DS condition was compared against a VM condition (see Figure 3B). Importantly, the RTs of the Set 1 absent trials in the DS condition were saved and subsequently used to determine the timing of the displays in the VM condition, in which the second set appeared automatically. In the VM condition, the first set never contained a target, whereas the second set could contain a target on $50 \%$ of the cases. The moment of onset of the second set was randomly chosen (without replacement) from the saved RT list of the preceding DS block, with the restriction that display sizes were the same. For instance, if, on a certain trial, the participant had correctly responded absent after $970 \mathrm{msec}$ to the first 10 items of display size 20 in the DS condition, the VM condition would contain a trial on which a first set of 10 items appeared for $970 \mathrm{msec}$, automatically followed by the second set. This way, all first-set items appeared for exactly the same length of time across the two conditions.

A clear problem with this method is that direct counterbalancing of task order is impossible. The VM block used the RTs from the DS block and was, therefore, always presented afterward. Any improvement in performance in the VM block could thus be attributed to practice effects. We therefore repeated the whole procedure for each participant - that is, after the first set of DS and VM blocks, they completed another DS block, followed by a last VM block. Any improvements owing to practice should then become evident in the second DS block; that is, if practice effects are solely responsible, the second DS block should be at least as efficient as the first VM block.

The response keys were $\mathrm{M}$ (present) and $\mathrm{Z}$ (absent) on the computer keyboard. The full-set, DS, and VM conditions were blocked,
A

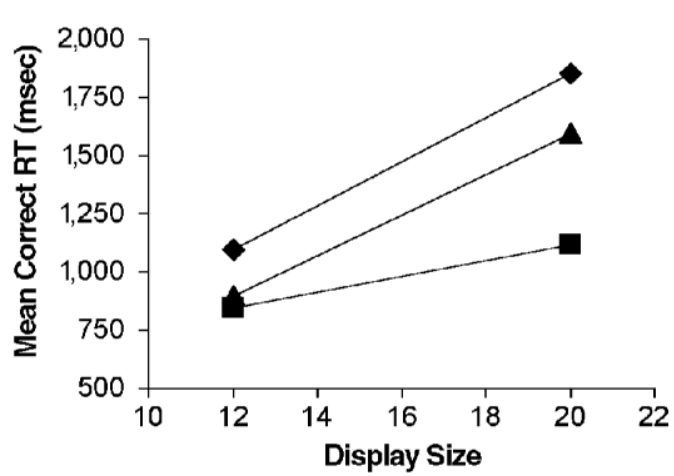

Present

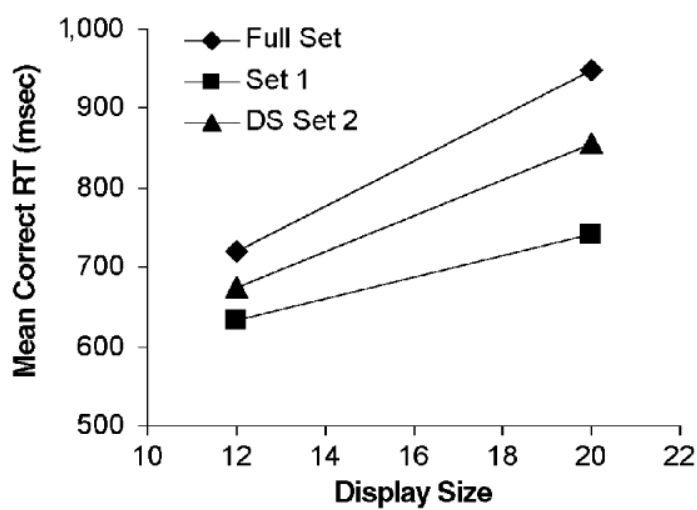

B

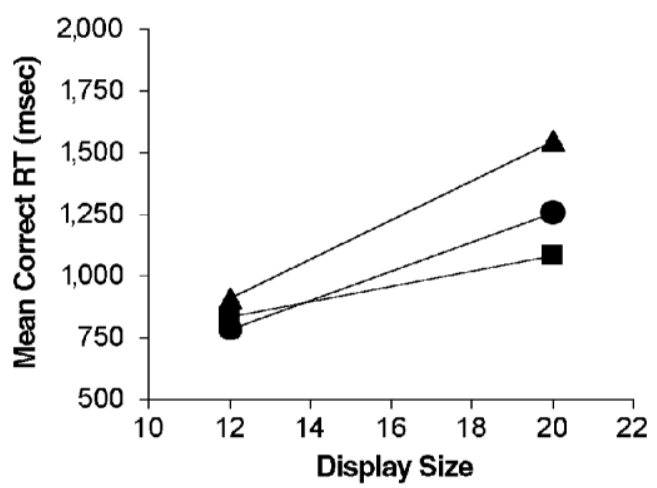

Present

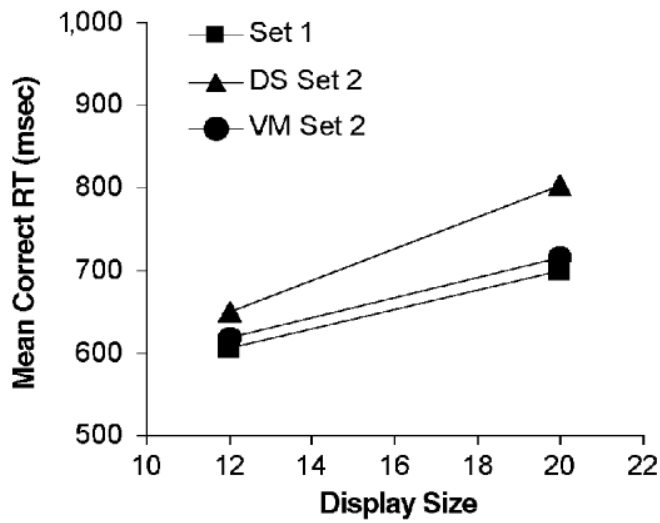

Figure 4. Mean response times (RTs) in Experiment 2. (A) Results for Experiment 2A, in which a double-search (DS) condition was compared with full-set and Set 1 baselines. (B) Results for Experiment 2B, in which the DS condition was compared with a visual-marking condition and a Set 1 baseline. 
Table 2

Error Percentages for Experiment 2

\begin{tabular}{|c|c|c|c|c|}
\hline \multirow[b]{2}{*}{ Experiment } & \multirow[b]{2}{*}{ Condition } & \multirow[b]{2}{*}{ Target } & \multicolumn{2}{|c|}{ Display Size } \\
\hline & & & 12 & 20 \\
\hline \multirow[t]{6}{*}{$2 \mathrm{~A}$} & Set 1 baseline & absent & 1.2 & 0.4 \\
\hline & & present & 1.3 & 3.1 \\
\hline & Full-set baseline & absent & 0.8 & 2.9 \\
\hline & & present & 3.8 & 4.5 \\
\hline & Double-search Set 2 & absent & 1.6 & 5.9 \\
\hline & & present & 4.7 & 4.5 \\
\hline \multirow[t]{6}{*}{$2 \mathrm{~B}$} & Set 1 baseline & absent & 1.1 & 1.2 \\
\hline & & present & 2.4 & 3.5 \\
\hline & Double-search Set 2 & absent & 1.5 & 7.4 \\
\hline & & present & 3.2 & 3.5 \\
\hline & Visual marking Set 2 & absent & 1.6 & 5.7 \\
\hline & & present & 5.3 & 4.7 \\
\hline
\end{tabular}

and each participant completed two blocks of each. In total, there were 100 trials in the full-set and VM conditions: 50 Set 2 present trials and 50 Set 2 absent trials. There were 200 trials in the DS condition, of which 100 trials had a target in the first set (Set 1 present), 50 trials had a target in the second set (Set 1 absent, Set 2 present), and 50 trials had no target at all (Set 1 absent, Set 2 absent). Each task started with 30 to 40 practice trials. The participants were allowed to move their eyes freely.

\section{Results, Experiment 2A}

The search functions are shown in Figure 4A. On targetabsent trials, full-set trials yielded a slope of $95 \mathrm{msec} / \mathrm{item}$, slopes for Set 1 trials were $33 \mathrm{msec} / \mathrm{item}$, and slopes for Set 2 trials were $87 \mathrm{msec} /$ item. On target-present trials, slopes were $29 \mathrm{msec} / \mathrm{item}, 13 \mathrm{msec} / \mathrm{item}$, and $22 \mathrm{msec} / \mathrm{item}$, respectively. As in Experiment 1, few errors were made (2.9\% overall; see Table 2), and the error pattern followed the RTs. The recursive clipping procedure eliminated $1.5 \%$ of the datapoints. The overall three-way search task (full set, Set 1 DS, Set 2 DS) $\times$ target $(a b-$ sent, present $) \times$ display size $(12,20)$ ANOVA revealed all interactions to be significant (all $p \mathrm{~s}<.001$ ). For clarity, therefore, we will report the separate comparisons on search performance for Set 2 items, relative to the two baselines (full set and Set 1).

DS Set 2 versus full set. There were significant search task $X$ target, search task $X$ display size, and target $X$ display size interactions $\left[F(1,13)=17.5, M S_{\mathrm{e}}=10,322\right.$, $p=.001 ; F(1,13)=9.9, M S_{\mathrm{e}}=2,265, p<.01 ; F(1,13)=$ $143.9, M S_{\mathrm{e}}=13,274, p<.001$, respectively]. The search task $\times$ target $\times$ display size interaction failed to reach significance $(p=.712)$. Search was least efficient on $a b$ sent trials, which were especially slow in the full set. Most important, search was overall more efficient for Set 2 items than for the full set.

DS Set 2 versus Set 1. All two-way interactions were significant ( $p$ s $<.001$ ), but an interpretation was not straightforward, because the three-way search task $\times$ target $\times$ display size interaction was also reliable $[F(1,13)=$ $\left.39.3, M S_{\mathrm{e}}=5,599, p<.001\right]$. For absent trials, there was a reliable search task $\times$ display size interaction $[F(1,13)=$ 49.5, $\left.M S_{\mathrm{e}}=12,946, p<.001\right]$ : Slopes were steeper for Set 2 . For present trials, the search task $\times$ display size interaction was also significant $\left[F(1,13)=11.9, M S_{\mathrm{e}}=\right.$ $1,573, p<.01]$. Thus, overall, in the DS task, there was less efficient search for Set 2 displays than for Set 1 displays.

\section{Results, Experiment 2B}

Error rates were again low (average across all conditions, $3.1 \%$; see Table 2). There was a tendency for more errors on present trials in Set 2 of the VM condition, relative to the Set 1 baseline $\left[F(1,18)=16.4, M S_{\mathrm{e}}=10.2\right.$, $p=.001]$. However, most important, there were no error slope interactions that contradicted the RT slope pattern, and we concluded that there were no speed-accuracy tradeoffs affecting the slopes of the functions. We will return to the error pattern in the Discussion section. The outlier elimination procedure removed $2.1 \%$ of the correct trials from further analyses. Figure $4 \mathrm{~B}$ shows the search functions averaged across blocks. On absent trials, the slopes measured $32 \mathrm{msec} /$ item for Set 1 displays, $60 \mathrm{msec} /$ item for the Set 2 displays in the VM condition, and $79 \mathrm{msec} / \mathrm{item}$ for the Set 2 displays in the DS condition. On present trials, slope values were $12 \mathrm{msec} / \mathrm{item}$, $12 \mathrm{msec} / \mathrm{item}$, and $19 \mathrm{msec} / \mathrm{item}$, respectively.

RTs were entered in an initial ANOVA with search task (Set 1, Set 2 DS, Set 2 VM), target (absent, present), and display size $(12,20)$ as factors. Again, all interactions were reliable, and we therefore report separate comparisons between the main conditions. The pattern of performance was very similar across blocks, although there were a few interactions. We will mention these together with the appropriate subanalyses. Furthermore, block will be a useful factor when we assess possible practice effects caused by a confounding in the present experimental design (see the Method section).

Set 2 DS condition versus Set 1 baseline. A comparison between Set 2 DS displays and Set 1 displays revealed a significant three-way interaction [search task $\times$ target $\times$ display size, $F(1,18)=66.4, M S_{\mathrm{e}}=3,685, p<$ $.001]$. This was broken down by separate analyses on $a b$ sent and present trials. On absent trials, slopes were reliably greater for Set 2 DS displays than for Set 1 displays, as was indicated by a significant search task $X$ display size interaction [79 msec/item vs. $32 \mathrm{msec} /$ item; $\left.F(1,18)=87.1, M S_{\mathrm{e}}=7,939, p<.001\right]$. An analysis with block as an additional factor revealed a significant block $\times$ search task $\times$ display size interaction $[F(1,18)=18.0$, $\left.M S_{\mathrm{e}}=3,513, p<.001\right]$. The slope difference was greater in the first block (96 msec/item vs. $38 \mathrm{msec} / \mathrm{item})$ than in the second (63 msec/item vs. $26 \mathrm{msec} / \mathrm{item})$. On present trials, Set 2 DS displays yielded higher slope values than did Set 1 displays [19 msec/item vs. $12 \mathrm{msec} / \mathrm{item}$; $\left.F(1,18)=8.2, M S_{\mathrm{e}}=2,135, p=.01\right]$. For these trials, there was no difference across blocks $(p=.640)$.

Set 2 VM condition versus Set 1 baseline. The search task $\times$ target $\times$ display size interaction was again significant $\left[F(1,18)=46.1, M S_{\mathrm{e}}=2,411, p<.001\right]$. On $a b$ sent trials, slopes were reliably greater for Set $2 \mathrm{VM}$ displays than for Set 1 baseline displays $[60 \mathrm{msec} /$ item vs. $32 \mathrm{msec} /$ item; search task $\times$ display size, $F(1,18)=37.5$, 
$\left.M S_{\mathrm{e}}=6,261, p<.001\right]$. On present trials, there was no overall difference between Set 2 VM displays and Set 1 baseline displays (search task, $p=.242$ ) and no interaction with display size (both $12 \mathrm{msec} /$ item). There were no interactions with block for absent or present trials $(p \mathrm{~s}>.11)$.

Set 2 DS condition versus Set 2 VM condition. A direct comparison between search through the Set 2 displays in the DS condition and the VM condition revealed another search task $\times$ target $\times$ display size interaction $\left[F(1,18)=7.8, M S_{\mathrm{e}}=3,328, p=.01\right]$. For absent trials, search was reliably less efficient in the DS condition [79 msec/item vs. $60 \mathrm{msec} /$ item; search task $\times$ display size, $\left.F(1,18)=18.5, M S_{\mathrm{e}}=6,529, p<.01\right]$, but more so in the first than in the second block [96 msec/item vs. $62 \mathrm{msec} / \mathrm{item}, 63 \mathrm{msec} / \mathrm{item}$ vs. $57 \mathrm{msec} /$ item; block $\times$ search task $\times$ display size, $F(1,15)=17.5, M S_{\mathrm{e}}=5,596$, $p=.001]$. In the second block, absent slopes did not reliably differ $(p=.237)$. Also, on present trials, search was less efficient in the DS condition than in the VM condition [19 msec/item vs. $12 \mathrm{msec} /$ item; search task $X$ display size, $\left.F(1,15)=9.3, M S_{\mathrm{e}}=1,515, p<.01\right]$. Here, there was no interaction with block $(p=.511)$.

Practice effects. The fixed experimental design (ABAB) led to a confounding in terms of practice: The VM condition (Blocks 2 and 4) was always presented after the DS condition (Blocks 1 and 3). We therefore performed the same analyses on Blocks 2 and 3 only, for which the order was VM followed by DS (i.e., a BA design). Note that the deck was now stacked against VM; that is, any practice effect would be in favor of the DS condition. Still, on present trials, search was more efficient in the VM condition (13 msec/item) than in the DS condition [18 msec/item; $F(1,18)=6, M S_{\mathrm{e}}=1,628, p<$ .05]. On absent trials, there was no difference between the DS and the VM slopes (63 msec/item vs. $62 \mathrm{msec} / \mathrm{item}$ ). Furthermore, on neither absent nor present trials was there a main effect of search task $\left(F_{\mathrm{S}}<1\right)$. Thus, the practice may have reduced overall RTs in the DS condition to the level of those in the VM condition, but it did not affect the relative efficiency of search. The error patterns for Blocks 2 and 3 were very similar to the overall pattern in Table 2 (DS with display size of 12, 3.3\%; DS with display size of $20,3.4 \%$; VM with display size of $12,5.3 \%$; VM with display size of 20,4.8\%).

\section{Discussion}

In Experiment 2A, the participants were given all the time necessary to search the first set of items before the second set appeared. Under these conditions, the DS condition did show some improvements, relative to a full-set baseline. This is consistent with memory's having a role in visual search, although other factors are likely to be responsible too. For instance, some of the new objects may capture attention automatically (Yantis \& Jonides, 1984; see also Experiment 3). Slopes for targetpresent trials were $22 \mathrm{msec} / \mathrm{item}$ for Set 2 items, relative to $29 \mathrm{msec} / \mathrm{item}$ for the full-set baseline. Nevertheless, search performance was still not as good as in the Set 1 baseline (13 msec/item). Apparently, searching the first set of items does not prevent observers from returning to at least some old items.

Experiment 2B demonstrated again that detection of targets in Set 2 displays in the VM condition was more efficient than that in the DS condition and that, in the VM condition alone, it was as efficient as when participants searched only one set of items (the Set 1 baseline). The benefit for target detection in the VM condition over the DS condition was not confounded by the fixed order of tasks. If the difference was due to practice, we would expect the size of the difference to decrease across blocks. However, on present trials, the advantage for VM trials did not interact with block. Indeed, the advantage in terms of search slopes for the VM over the DS condition held even when the trials on Block 2 (VM) were compared with those on Block 3 (DS; when any practice effects would go against the VM condition). In Experiment 3, we will again consistently stack the odds against $\mathrm{VM}$ and will find once more that the DS condition is less efficient than the VM condition. We are therefore confident that the present effects are not due to practice. Note also that, although Set 1 intervals were exactly matched across blocks, timing conditions were actually nonoptimal in the VM task, since the moment of onset of Set 2 displays was uncertain in that condition. The conclusion of Experiment 1 is, therefore, further supported: Search leads to imperfect memory for old items, whereas the VM condition allows old items to be ignored completely. The preview effect is therefore likely to involve different processes than those applied in visual search.

On absent trials, the slopes for all the conditions were generally higher, and any advantage for the VM condition over the DS condition was weaker and was eliminated by practice. This is not very surprising. On absent trials, the participants often may have been uncertain about the presence of the target and may well have adopted the strategy of returning to all the items in the displays (old Set 1 as well as new Set 2 stimuli), in order to minimize errors. Consistent with this, in the VM condition, the absent search slope (60 msec/item) measured five times the present search slope (12 msec/item), indicating that considerable rechecking of displays took place. No advantage for the VM condition would be expected for such an exhaustive search.

Although in Experiment 2, we tried to make sure that the participants were better prepared for the second set in the DS condition, one may object that the target was twice as likely to appear in the first set as in the second set (since Set 2 trials were contingent upon Set 1 absent trials). The difference in probability may have caused the observers to focus on the first set more and/or be willing to disengage from the first set less. However, we believe that the nature of the task makes this possibility unlikely. The participants knew that the second set would appear only if they correctly decided absent on the first set. Hence, they knew that by the time the second set ap- 
peared, the target was definitely not in the first set and, if present, should be in the second set. In fact, many of the participants reported that they actually expected the target to be present in Set 2 once they had decided it was absent in Set 1, even though the probability of a target was then still only $50 \%$. The error pattern seems to confirm this bias toward Set 2 target-present responses, since the participants made fewer target-present errors and slightly more target-absent errors in the Set 2 DS condition, relative to the Set $2 \mathrm{VM}$ condition, resulting in a significant search task $\times$ target interaction $[F(1,18)=$ $\left.6.1, M S_{\mathrm{e}}=17.1, p<.05\right]$. Nevertheless, in Experiment 3, we took away any differences in target probability between Set 1 and Set 2, and we found essentially the same results.

\section{EXPERIMENT 3 Spread Versus Focused Attention}

An important question is why, as compared with the VM condition, searching the old items in the DS condition is so detrimental to the prioritization of new items. From a mnemonic search point of view, one possibility may be that the initial search is too demanding. A serial scan may consume resources that otherwise would be used to memorize or inhibit already searched items. Note that this argument would be very ironic, since it also has been suggested that such an attentional scan is exactly what is required to create a memory trace (or inhibition of return) in the first place (see Klein, 1988; Logan, 1988; Müller \& von Muhlenen, 2000; Takeda \& Yagi, 2000; Treisman et al., 1992). Nevertheless, it may be that for one reason or another, both mnemonic search and inhibition of return would benefit more if search was easier and attention, therefore, more distributed.
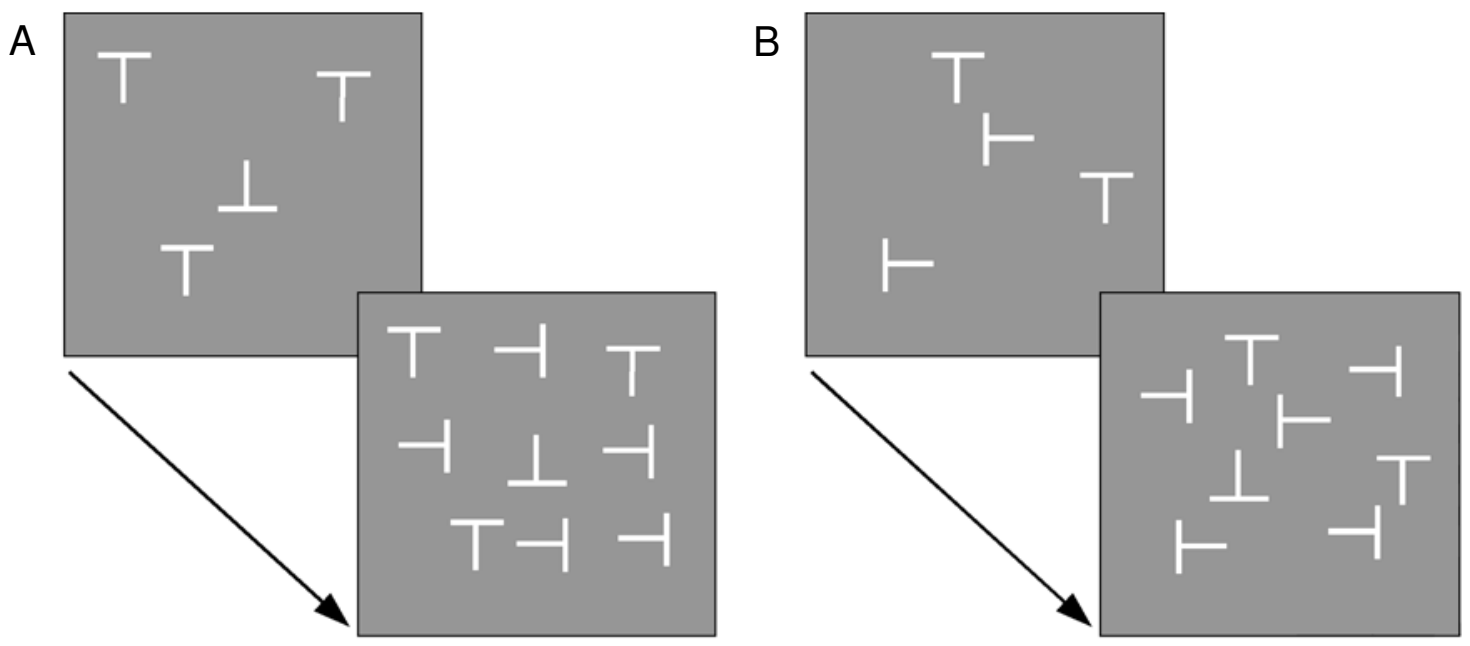

Figure 5. Examples of the (A) easy Set 1 search and (B) difficult Set 1 search conditions of Experiment 3A. In the easy Set 1 search condition, the target is present in the first set and absent in the second. In the difficult Set 1 search condition, the target is absent in the first set and present in the second. In the number judgment condition of Experiment 3B, the displays would look like those in (B), but the participants had to determine the number of old items (here, few) instead. 
stead, observers merely had to judge the number of items in Set 1 -that is, they only had to say whether there were a few items (when there were four) or many items (when there were eight). We assumed that this number judgment (NJ) task was an easy task, which participants could perform under a relatively distributed state of attention (i.e., in parallel, as was confirmed by the results). The first set was then followed by the addition of a second set, which had to be searched. Again, we compared this second-set search with a VM condition, with the same set of predictions: If having to actively involve the old items in a task is detrimental to the prioritization of new items, this should show here.

\section{Method}

Participants. Twenty-nine students from the University of Birmingham participated for money or course credit, of which 8 took part in Experiment 3B. The average age was 23.7 years (range, 19-33). Twelve were male, and 3 were left-handed. Initially, 21 participants took part in Experiment 3A. However, not all the participants were included in the analysis. Note that we want to test for possible differences in prioritization between the case in which observers perform an effortful (serial) attentional scan through the old items and the case in which observers need to actively attend, but not scan, the old items. However, some participants did not show much difference between the easy and the difficult Set 1 search conditions in the first place, with rather high slopes in both conditions. In other words, for some participants, the easy search task was attentionally demanding too, and it would therefore not be too surprising if we did not find a difference between a second-set search after an easy search and a second-set search after a difficult search. In order to maximize our test of potential differences between easy and difficult search, we therefore removed all the participants with easy search slopes exceeding $10 \mathrm{msec} /$ item on target-present trials. The final analysis includes 14 participants whose average search slopes were 4 (present) and 12 (absent) $\mathrm{msec} /$ item in the easy search condition and 20 (present) and 40 (absent) msec/item in the difficult search condition. It deserves mentioning, however, that the results were largely unaltered by this selection procedure.

Stimuli and Apparatus. The experimental set-up was the same as those in Experiments 1 and 2. The stimuli were different, however, and now consisted of capital Ts in various orientations (see Figure 5). The Ts were presented in white on a gray background and fell inside a square matrix measuring $10.6^{\circ} \times 10.6^{\circ}$ of visual angle. The Ts themselves were approximately $0.7^{\circ}$ high $\times 0.7^{\circ}$ wide and could be one of four orientations: upright, $90^{\circ}$, inverted, and $270^{\circ}$. Total display sizes were 8 and 16 .

Design and Procedure. See Figure 5 for a typical example display sequence. In Experiment 3A, there were two Set 1 search conditions. In the diff icult search condition, Set 1 search displays were heterogeneous, consisting of upright Ts, and Ts rotated $90^{\circ}$. The target, if present, was an inverted T. In the easy search condition, Set 1 displays were homogeneous, consisting only of upright Ts and, possibly, an inverted-T target. Both sets were followed by a second set consisting of Ts rotated $270^{\circ}$, and, if present, an inverted-T target. In the DS condition, the participants had to search Set 1 for the presence of an inverted-T target. Upon their (correct) response, the second set was added to the first, and now the participants had to search this second set, which could again contain an inverted T. If the response to the first set was incorrect, the trial was terminated. One of the differences with Experiment 2 was that Set 2 appearance was now not contingent upon Set 1 absent responses, but occurred regardless of whether or not a target was present in Set 1. Target presence in Set 2 was completely independent of target presence in
Set 1 . Thus, there were equal numbers of the following trial types: Set 1 present-Set 2 present; Set 1 present-Set 2 absent; Set 1 absentSet 2 present; Set 1 absent-Set 2 absent. Note that this means that, on some trials, there were two targets, one belonging to the old set and one belonging to the new set.

Display types and sequences in the VM condition were exactly the same, but without the participant's being required to respond to Set 1 . The second set appeared automatically after a timing interval matched to the DS condition (see Experiment 2 for the method). We now solved the counterbalancing problem by repeating the DS and VM blocks 42 times and then taking away the first DS block and the last VM block from the analyses, leaving 10 blocks for each task. This resulted in a VM-DS order for every participant. Any practice effects would thus go against VM.

All tasks (DS easy, DS difficult, VM easy, VM difficult) were blocked, and each block contained 16 trials, 2 for each Set 1 target (absent, present) $\times$ Set 2 target (absent, present) $\times$ display size $(8$, 16) combination. Erroneous trials were repeated by randomly inserting them in the remaining trials (new displays were generated for these trials). At the end of the experiment, each cell contained 20 datapoints. The participants first practiced each task once (16 trials per task). In Experiment 3B, the procedure was very similar. However, instead of having to search the first set in the DS condition, the participants simply had to decide whether there were few (four) or many (eight) old items. In this NJ condition, the old set was heterogeneous. We compared the NJ condition to a VM condition with the same type of displays, but without the NJ task. Again, the tasks were blocked, with 16 trials per block.

\section{Results, Experiment 3A}

As before, correct trials and errors were analyzed separately. Of the correct RTs, $2.53 \%$ were lost owing to the outlier removal procedure. Descriptive statistics are plotted in Figure 6.

RTs, Set 1 search. As is not surprising, given our participant selection procedure (see the Method section), there were differences between the easy and the difficult search tasks. As can be seen from Figure 6A, RTs were faster in the easy search condition than in the difficult search condition, as was confirmed in an ANOVA [search difficulty, $F(1,13)=134.8, M S_{\mathrm{e}}=18,843, p<$ $.001]$. Moreover, search was much more efficient in the easy condition than in the difficult condition, as was confirmed by a significant search difficulty $\times$ display size interaction $\left[F(1,13)=68.0, M S_{\mathrm{e}}=3,224, p<.001\right]$. A separate analysis showed that this held for both present and absent trials ( $p$ s $<.001)$ but that the effects were greater for absent trials than for present trials, resulting in a significant search difficulty $X$ display size $X$ target interaction $\left[F(1,13)=5.85, M S_{\mathrm{e}}=2,697, p<.05\right]$. In the easy search task, slopes measured $4 \mathrm{msec} /$ item and $12 \mathrm{msec} /$ item for present and absent trials, respectively, whereas in the difficult task, slopes measured $20 \mathrm{msec} /$ item and $40 \mathrm{msec} / \mathrm{item}$, respectively.

Set 2 search. The next step was to determine the consequences of search through the first set for search through the second set and whether any consequences differed for easy and difficult Set 1 searches. The presence of the first target (in Set 1) had few effects on search through Set 2 . There was a significant main effect $\left[F(1,13)=10.3, M S_{\mathrm{e}}=13,329, p<.01\right]$, plus one signif- 
A Set 1 Absent \& Present

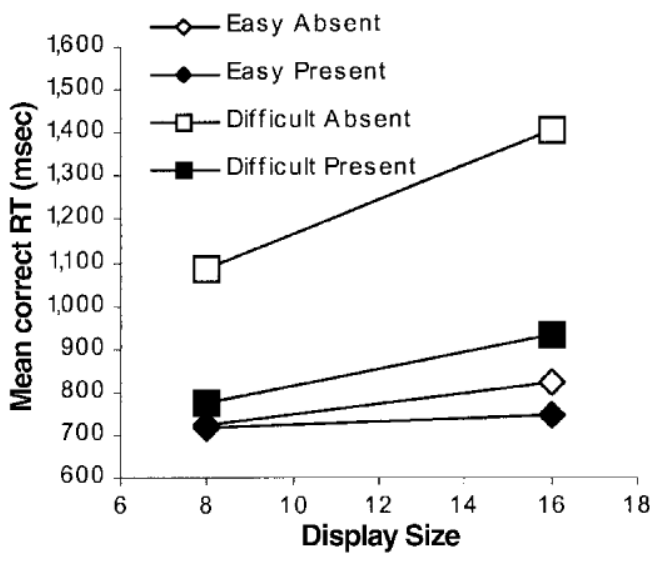

B Set 2 Absent Trials

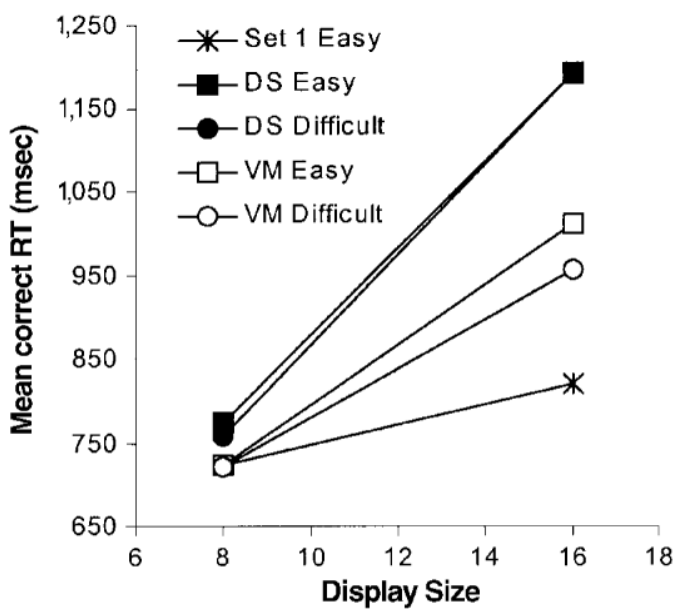

C Set 2 Present Trials

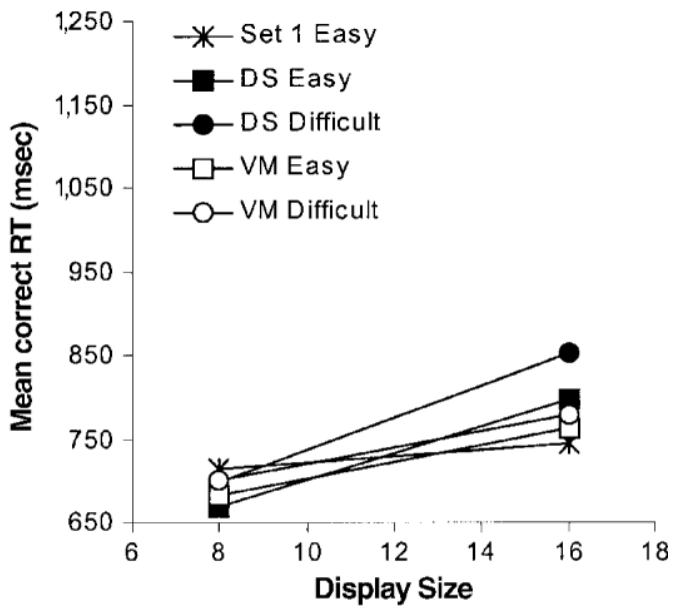

Figure 6. (A) First-set search performance for Experiment 3A. Bottom: Second-set search performance for (B) absent trials and $(C)$ present trials. DS, double search; VM, visual marking.

icant two-way interaction [first target $\times$ second target, $\left.F(1,13)=9.0, M S_{\mathrm{e}}=5,150, p=.01\right]$. On average, search through the second set was about $35 \mathrm{msec}$ slower when a target had appeared in the first set. This may be because the participants were sometimes confused as to which set the target belonged to. However, this did not differentially affect search in the VM and DS conditions, nor did it interact with display size, search task, and search difficulty or with their higher order interactions (all $p \mathrm{~s}>.13$ ). Hence, first target is not further reported as a factor, and Figures $6 \mathrm{~B}$ and $6 \mathrm{C}$ show the search functions collapsed accordingly.

On absent trials, the slope values were $52 \mathrm{msec} / \mathrm{item}$ for DS easy, $54 \mathrm{msec} / \mathrm{item}$ for DS difficult, $36 \mathrm{msec} / \mathrm{item}$ for VM easy, and $30 \mathrm{msec} /$ item for VM difficult. The present slopes measured $16 \mathrm{msec} /$ item for DS easy, $19 \mathrm{msec} /$ item for DS difficult, $10 \mathrm{msec} /$ item for VM easy, and $10 \mathrm{msec} / \mathrm{item}$ for VM difficult. It should be noted that there is no real baseline against which we can compare this performance. Second-set search, when successfully eliminating all old items, should be a search through a homogenous set of an inverted-T among $270^{\circ}$-rotated Ts. The closest approximation to a homogenous baseline is the Set 1 easy search, which involved an inverted $\mathrm{T}$ among upright Ts. Search through Set 2 was less efficient than this first easy search for all the conditions (DS and VM, all $p$ s <.01). This may indicate that even in the VM condition, the deprioritization of old items was not entirely successful. However, the two homogeneous searches may differ substantially. For instance, the upright-T distractors in the easy Set 1 task are more familiar (as letters) and may, therefore, be more easily rejected as distractors (Greene \& Rayner, 1999; Rauschenberger \& Yantis, 1999; Wang, Cavanagh, \& Green, 1994; see also Humphreys \& Müller, 1993, for similar arguments). Furthermore, those participants who were inefficient in the easy Set 1 condition are not included in the results, possibly deflating the easy Set 1 
Table 3

Error Percentages for Experiment 3

\begin{tabular}{|c|c|c|c|c|c|}
\hline \multirow[b]{3}{*}{ Experiment } & \multirow[b]{3}{*}{ Condition } & \multicolumn{4}{|c|}{ Target/Display Size } \\
\hline & & \multicolumn{2}{|c|}{ Absent } & \multicolumn{2}{|c|}{ Present } \\
\hline & & 8 & 16 & 8 & 16 \\
\hline \multirow[t]{6}{*}{$3 \mathrm{~A}$, Set 1 search task } & Set 1 easy & 1.5 & 1.6 & 2.5 & 2.6 \\
\hline & Set 1 difficult & 2.5 & 1.3 & 3.6 & 6.8 \\
\hline & Set 2 DS easy & 1.3 & 4.0 & 4.6 & 9.0 \\
\hline & Set 2 DS difficult & 1.2 & 1.8 & 4.8 & 15.8 \\
\hline & Set 2 VM easy & 3.3 & 5.8 & 5.2 & 13.3 \\
\hline & Set 2 VM difficult & 2.0 & 5.3 & 6.3 & 13.6 \\
\hline \multirow[t]{3}{*}{$3 \mathrm{~B}$, Set 1 number task } & Set $1 \mathrm{NJ}$ & 3.8 & 5.2 & & \\
\hline & Set 2 NJ & 3.9 & 4.8 & 6.4 & 15.1 \\
\hline & Set 2 VM & 2.4 & 7.1 & 5.5 & 12.3 \\
\hline
\end{tabular}

Note-In Experiment 3A, the first set was searched in the DS condition. In Experiment 3B, the first set was assessed on the number of items it contained (no target present). DS, double search; VM, visual marking; NJ, number judgment.

slope, relative to the Set 2 slope. We therefore report only on the DS versus VM comparison, which is where our main interest lies.

DS versus VM, absent trials. When directly comparing the two types of second-set search (DS and VM), we found overall RTs to be significantly greater in the DS condition [task, $\left.F(1,13)=15.4, M S_{\mathrm{e}}=58,441, p<.01\right]$. Furthermore, search was less efficient in the DS condition, as indicated by increased search slopes [search task $\times$ display size, $\left.F(1,13)=21.1, M S_{\mathrm{e}}=18,062, p=.001\right]$. Importantly, there were no effects of search difficulty $(p s>.31)$.

DS versus VM, present trials. Slightly different results were found when present trials were compared. There was now no overall effect of search task. Instead, there was a small but reliable overall effect of search difficulty $\left[F(1,13)=9.0, M S_{\mathrm{e}}=5,498, p=.01\right]$. Importantly, search was again less efficient in the DS condition [search task $X$ display size, $\left.F(1,13)=20.5, M S_{\mathrm{e}}=2,581, p=.001\right]$, whereas search difficulty had no influence on the slopes $(p=.282)$. No other interactions were significant.

Errors. Error percentages are shown in Table 3. The overall error rate was 5\%. Errors largely followed the RT data, with one anomaly. Overall, more errors were made in the second-set conditions (DS as well as VM) than in the baseline condition, and their error slopes were steeper too [search task, $F(2,26)=33.6, M S_{\mathrm{e}}=39.5, p<.001$; search task $\times$ display size, $F(2,26)=9.3, M S_{\mathrm{e}}=47.9$, $p=.001]$. There was no overall search difficulty $\times$ display size interaction ( $p=.315$; also, no search task $\times$ search difficulty $\times$ display size interaction, $p=.212$ ), suggesting that Set 1 search difficulty had no effect on Set 2 error rates. Comparing only the DS and the VM conditions revealed no overall difference in error slopes (search task $\times$ display size, $p=.60$ ) and no difference in slopes between easy and difficult search (search difficulty $\times$ display size, $p=.32$; also, no search task $\times$ search difficulty $\times$ display size interaction, $p=.19$ ). However, there was a complex four-way search task $X$ search difficulty $\times$ display size $\times$ target interaction.
Breaking this interaction down into separate analyses indicated that, on present trials of the DS condition, secondset search suffered more after a difficult search than after an easy search, whereas on absent trials, the effects went in the other direction (search suffered more after an easy than after a difficult Set 1 search). In the VM condition, there was little effect of the Set 1 task. A further breakdown indeed suggested a trend for present trials on the easy task to lead to fewer errors in the DS condition $\left[F(1,13)=3.77, M S_{\mathrm{e}}=26.3, p=.074\right]$, but there was a similar trend in the opposite direction for absent trialsthat is, to lead to fewer errors on the difficult task of the DS condition $\left[F(1,13)=4.38, M S_{\mathrm{e}}=11.34, p=.057\right]$. All in all, these results seem, therefore, to be best explained as a change in accuracy bias within the DS condition. After the participants had completed a difficult search, they were a little more careful and prone to respond absent; in contrast, after an easy first-set search, the participants tended to respond target present more readily. It deserves mentioning, however, that overall, on average, there was no difference in error slopes between the VM and the DS conditions (both at .96).

\section{Results, Experiment 3B}

RTs. Figure 7 shows the average search functions for Experiment 3B. The outlier removal procedure excluded $2.7 \%$ of the datapoints from the analyses. The results were relatively straightforward. The participants conducted the NJ task efficiently, since there was no effect of display size ( $3 \mathrm{msec} / \mathrm{item}, p=.163$ ). Search through the second set was slower for absent trials than for present trials and also was slower for the larger display sizes $\left[F(1,7)=7.2, M S_{\mathrm{e}}=27,087, p<.05\right.$, and $F(1,7)=55.8$,

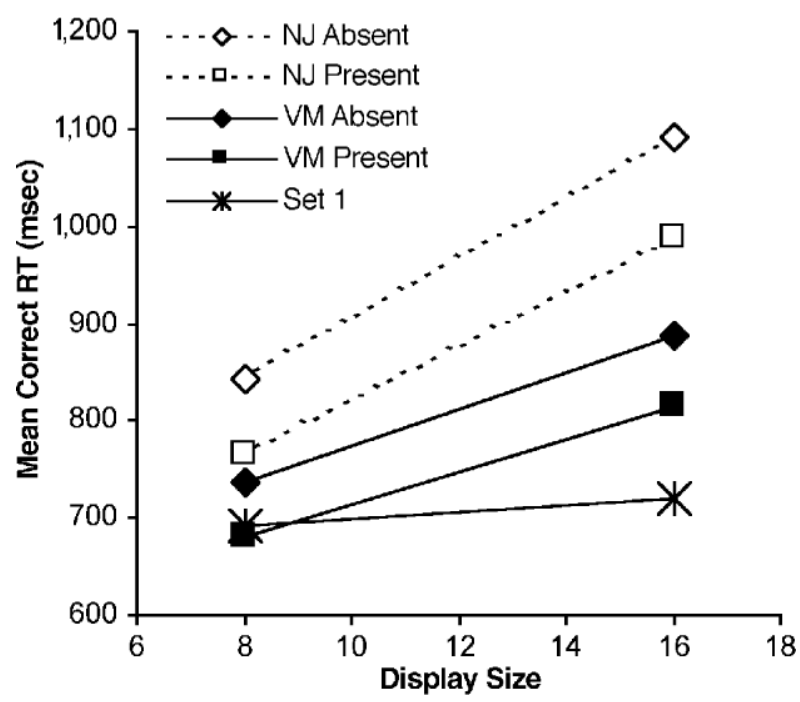

Figure 7. Results from Experiment 3B, in which the participants had to judge the number of old items before searching the second set (number judgment $[\mathrm{NJ}]$ condition) or plainly ignore the old items (visual-marking [VM] condition). 
$M S_{\mathrm{e}}=20,526, p<.001$, respectively]. Importantly, search through the second set differed, depending on how the first set was treated. Search was overall slower in the NJ condition than in the VM condition $[F(1,7)=$ $\left.20.1, M S_{\mathrm{e}}=31,962, p<.01\right]$. Moreover, search was less efficient in the $\mathrm{NJ}$ condition than in the VM condition $\left[F(1,7)=14.6, M S_{\mathrm{e}}=5,003, p<.01\right]$, with slope values of $31 \mathrm{msec} /$ item and $28 \mathrm{msec} /$ item in the dual-task condition and $19 \mathrm{msec} /$ item and $17 \mathrm{msec} /$ item in the VM condition (absent and present trials, respectively). There were no further interactions.

Errors. The error rates generally followed the RTs (see the bottom panel of Table 3). Overall, in the secondset search, more errors were made on present trials, and errors also increased with display size $[F(1,7)=5.6$, $M S_{\mathrm{e}}=160.7, p=.05$, and $F(1,7)=19.3, M S_{\mathrm{e}}=46.3, p<$ .01 , respectively]. Furthermore, error slopes across display size were steeper for present than for absent trials $\left[F(1,7)=9.4, M S_{\mathrm{e}}=20.8, p<.05\right]$. There were no signs of differences in speed-accuracy tradeoff between the $\mathrm{NJ}$ and the VM conditions.

\section{Discussion}

The results are similar to those of Experiment 2. Search through the second set was slower and less efficient when the participants had just searched the first set (in the DS condition), as compared with when they were given the opportunity to fully ignore the first set (in the VM condition). Once more, this suggests that searching the old items is not sufficient to create a perfect memory for to-be-ignored items. When the participants are given the opportunity to visually mark the old items, new items are better prioritized.

The most interesting result in Experiment $3 \mathrm{~A}$ was the lack of an improvement in search efficiency with the easy Set 1 search task in the DS condition. The easy search task allowed the participants to distribute their attention more evenly across the display (as was indicated by the smaller search slopes). Yet subsequent search rates through the second set were little better than when the participants had just searched a difficult display, and search was still considerably worse than in the VM condition. This result was further corroborated by Experiment $3 \mathrm{~B}$, in which the participants efficiently determined how many items were present in the first display. Even though this task could be conducted without having to focus attention on any of the old items, new items were still not as efficiently prioritized as in the VM condition.

These findings have a number of implications for explaining why the DS condition leads to relatively impaired prioritization of the second set. First, it is apparently not only a serial search that causes the disruption. When search through the old items was not serial (as in the easy Set 1 condition of Experiment 3A) or the items were not searched at all (Experiment 3B), Set 2 search was still relatively inefficient. Thus, it is unlikely that the disruption is due only to factors related to an effortful scan, such as a lack of attentional resources. Instead, the data are more consistent with a second explanation, which states that having to perform a task on the old items means that these items will be kept sufficiently active to subsequently interfere with search. Whether this task is relatively easy or difficult seems to make little difference. Apparently, it is the act of having to explicitly attend to the old items that disrupts prioritization of the new items. Such an active attentional set may interfere with, or prevent the set-up of, an inhibitory attentional set, giving VM little chance of being implemented.

Nevertheless, in Experiment 3A, there was an overall improvement on RTs for the easy search on present trials, and this effect was most pronounced in the DS condition. Possibly, there may be a slight improvement in either memory (for old items) or attentional capture (for new items; see Yantis \& Jonides, 1990). This improvement was equivalent to one fewer old item's being searched. Alternatively, there may be a decrease in the overall taskswitching costs in the easy condition, as compared with the difficult condition. The relative increase in the difficult search may also reflect the difference in stimuli. When old items are included in Set 2 of the difficult displays, they will form a more heterogeneous set, relative to when the same process occurs with the easy displays, resulting in slower search.

\section{EXPERIMENT 4 \\ Having to Respond Does Not Interfere With Second-Set Search}

The experiments so far seem to suggest that actively paying attention (whether focused or spread) to old items is not sufficient for, and is even detrimental to, the successful prioritization of search for new objects. One remaining concern, however, is that in all the DS conditions (except in Experiment 1), the participants had to perform an extra task, accompanied by an overt response. In the VM conditions, the participants did not need to make a response to Set 1 displays. Thus, any costs in the DS conditions may have arisen from task switching or response-related factors, rather than from attentional processing of the first set.

To control for this, in Experiment 4, the participants conducted a VM task identical to that in Experiment 3, with a homogeneous first set of upright Ts and no response to Set 1 displays. In addition to this VM condition, they also conducted a VM task in which they had to respond to the first set. This double-response (DR) condition was achieved in the following way. A first set of upright-T distractors was presented for $850 \mathrm{msec}$, which should be sufficient for VM to be established (Watson \& Humphreys, 1997). Then, a central T was presented for $150 \mathrm{msec}$, while the first set remained on the screen. The observers had to decide whether the central $\mathrm{T}$ was a target (upside-down T) or not, by pressing one of two response keys. Following this response, the second set was exposed, and the participants had to search the second set for a target (upside-down T). If response factors were 


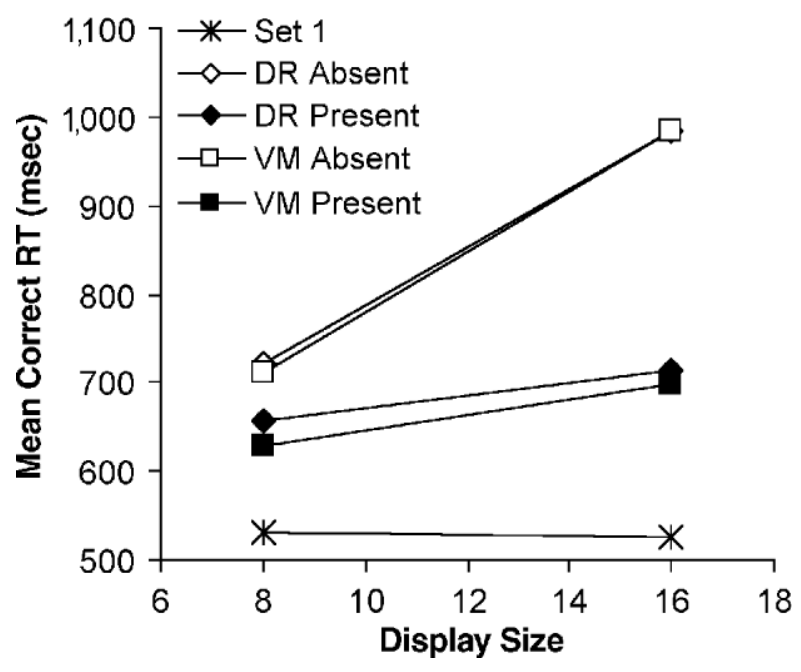

Figure 8. Response time (RT) results of Experiment 4. DR, double-response condition; VM, visual-marking condition.

responsible for worse search of second set displays, we would expect slopes to Set 2 displays to be greater after the participants had responded to the central task.

\section{Method}

Participants. Thirteen participants took part voluntarily or for payment. Four were male, and 1 was left-handed. The average age was 26.1 years (range, 20-30).

Stimulus and Apparatus. The stimuli and set-up were the same as those for the easy search conditions of Experiment 3A.

Design and Procedure. The design and procedure were similar to those in Experiment 3A, with a few exceptions. We replaced the DS task with a DR task, in which the participants were not required to search the first set but, nevertheless, had to respond to it. Also, we did not manipulate the diff iculty of the search displays. All first displays consisted of homogeneous sets of upright-T distractors. In the DR task, the participants previewed a first set of upright Ts for $850 \mathrm{msec}$, after which another $\mathrm{T}$ would flash up for $150 \mathrm{msec}$ in the center of the screen (at fixation). The participants determined whether the central $\mathrm{T}$ was an inverted $\mathrm{T}$ or not (by pressing one of two buttons), upon which the search set appeared. The participants were instructed to retain their fixation at the center of the screen during the first display. Across 20 blocks, 20 correct datapoints were gathered for each data cell. The participant practiced each task once (20 trials per task).

\section{Results}

Figure 8 shows the search functions, as well as performance at the central task. The outlier removal procedure excluded $2.53 \%$ of the datapoints. As would be expected, the central task was unaffected by the number of distractors (slopes measured $-1.9 \mathrm{msec} / \mathrm{item}$ and $0.8 \mathrm{msec} / \mathrm{item}$ for absent and present trials, respectively). The slope values of the second-set search task were as follows: $32.8 \mathrm{msec} /$ item for DR-absent trials, $7.3 \mathrm{msec} /$ item for DR-present trials, $34.1 \mathrm{msec} / \mathrm{item}$ for VM-absent trials, and $8.8 \mathrm{msec} / \mathrm{item}$ for VM-present trials.

RTs, central fixation task. The ANOVA revealed only an effect of target $\left[F(1,12)=25.5, M S_{\mathrm{e}}=1,870, p<\right.$
$.001]$. The average RT was $496 \mathrm{msec}$ for target trials and $560 \mathrm{msec}$ for nontarget trials. The identity of the central target did not interact with any other factors (all $p \mathrm{~s}>$ .39 ), and it is therefore dropped from further reports below.

DR versus VM. An ANOVA with search task (DR, $\mathrm{VM}$ ), target (now the second target), and display size as factors revealed no differences between the two conditions whatsoever (in terms of RTs, as well as slopes; search task, $p=.297$; search task $\times$ display size, $p=$ .277). The only significant effects were those for target $\left[F(1,12)=19.1, M S_{\mathrm{e}}=93,247, p=.001\right]$ and display size $\left[F(1,12)=44.5, M S_{\mathrm{e}}=34,179, p<.001\right]$, and there was a significant target $\times$ display size interaction $[F(1,12)=$ $\left.17.6, M S_{\mathrm{e}}=31,909, p=.001\right]$. RTs for absent trials were slower than those for present trials, and RTs increased with display size, but more so for absent trials than for present trials.

Errors. The error data are shown in Table 4. Overall, $4.1 \%$ errors were made. The pattern did not suggest any speed-accuracy tradeoffs. There was only a display size effect, with more errors for larger display sizes $[F(1,12)=$ 13.3, $\left.M S_{\mathrm{e}}=17.7, p<.01\right]$, and a strong hint of a target effect, with fewer errors on absent trials $[F(1,12)=4.2$, $\left.M S_{\mathrm{e}}=56.7, p=.062\right]$. Importantly, there was no main effect of search task, nor were there any reliable interactions $(p s>.202)$.

\section{Discussion}

Search in the DR condition was just as efficient as in the VM condition. Clearly, having to respond to the first display per se does not disrupt search through the second set. This indicates that the costs found in the DS conditions of Experiments 1,2, and 3 are not due to task switching or response selection mechanisms.

Furthermore, the results are consistent with the hypothesis that it is not having to spend attentional resources per se (during the preview period) that makes old items interfere more with second set search, but having to attend to the old items. In the present experiment, the participants were required to perform a task during the preview period, but not on the old items. Old items could therefore be safely deactivated by VM while performing the secondary task.

Perhaps it is somewhat surprising that VM is still so effective in the dual-task condition. Previous studies have shown that VM can be severely disrupted by a sec-

Table 4

Error Percentages for Experiment 4

\begin{tabular}{lll}
\hline & \multicolumn{2}{c}{ Display Size } \\
\cline { 2 - 3 } Condition & 8 & 16 \\
\hline Set 1 & 2.4 & 2.8 \\
DR absent & 3.5 & 5.2 \\
DR present & 4.7 & 7.6 \\
VM absent & 2.3 & 4.3 \\
VM present & 3.6 & 6.9 \\
\hline
\end{tabular}

Note—DR, double response; VM, visual marking. 
ondary task presented centrally (Olivers \& Humphreys, 2002b; Watson \& Humphreys, 1997). Such results support the conclusion that VM is a top-down mechanism, requiring resources in order to implement the inhibition. So why did the present secondary task not have a similar effect here? There are two likely reasons, which relate to the timing relations between the old items and the secondary task and to the difficulty of the secondary task. Recent experiments in our laboratory (Humphreys, Watson, \& Jolicœur, in press) suggest that a dual task particularly affects performance when it is coincident with the initial appearance (onset) of the old items. The secondary task creates less interference when presented after the old items have been in the field for some period. This is consistent with the secondary task's disrupting the "set-up" of the marking state more than the maintenance of inhibition to the old items. In the present study, the secondary task started $850 \mathrm{msec}$ after the onset of the old items, a period sufficiently long to optimize preview effects (Watson \& Humphreys, 1997). Hence, the present secondary task should not disrupt the set-up of the marking state. In addition, the secondary task was relatively easy, requiring discrimination of a single item, so that disruptive effects on the maintenance of marking would also be minimized.

\section{GENERAL DISCUSSION}

We investigated whether the preview benefit in search (Watson \& Humphreys, 1997) was due to a memory of, or inhibition of return to, locations previously subject to a visual search. We assessed whether participants are able to completely ignore objects they have just searched, by requiring observers to search a first display prior to a second set of items being added. Our evidence indicates that participants are not able to prevent themselves from inspecting previously searched locations and, hence, that the preview benefit is unlikely to be due to a memory or inhibition of return as created by an attention-demanding search of old items. In Experiments 1-3, an already searched set of items still interfered with search through a newly added set, resulting in higher slope values in DS conditions than would be expected if search was limited to the new items only. This finding has important implications for the study of memory processes in visual search. Apparently, memory for already searched items is either not very strong or not very precise.

In contrast, under conditions in which search of the first set is not encouraged (the VM conditions), performance was consistently better than in the DS conditions, and it was often as good as in a single-set baseline condition. Experiments 3 and 4 indicated that the benefit for the VM condition was not due just to a more distributed state of attention or to effects of task switching; nor was it due to the absence of a response to the first set. It follows that whatever mechanisms are used in search to prevent the return of attention to previously inspected items, they are not sufficient to account for the preview benefit.

\section{Active and Inactive Old Items}

Experiment 3 further suggested that it is not just an effortful search through old items that affects the prioritization of new items. Easy search and NJ tasks, which could both be conducted with a more distributed attentional state, were equally disruptive. We concluded that it is the fact that old items need to be actively attended and processed that prevents them from being ignored completely. Perhaps, at first glance, this is not too surprising. However, remember that it was exactly the basic crux of the hypothesis at hand. Under the assumption that memory or inhibition of return in visual search requires that attention be paid properly to old items (e.g., Klein, 1988), these processes should have benefited from the DS conditions. In particular, if VM involves similar attentional processing of old items, performance in the DS and the VM conditions should have been the same. Yet it clearly was not, suggesting that the preview effect is based on different processes.

On the other hand, we do not wish to suggest that VM does not involve attentive processing of old items. As was mentioned earlier, we have found, in various experiments, that the preview effect suffers from secondary tasks presented during the preview period. We have argued that such secondary tasks take attentional resources away from the top-down inhibitory process we envisage VM to be. This may sound paradoxical. On the one hand, we propose that attention is required for successful VM (as is suggested by the dual-task experiments), yet, on the other hand, we suggest that paying attention to old items is detrimental to the prioritization of new items (as is indicated by the present paper). However, we believe that these are two inherently different situations. In the first case, observers want to ignore the old items from the start, because these are irrelevant to the task. Yet the secondary task prevents them from doing so because, we believe, the engagement of attention elsewhere prevents an inhibitory attentional set from being set up or limits the resources available for the actual suppression (e.g., Humphreys et al., in press; Olivers \& Humphreys, 2002b; Watson \& Humphreys, 1997). In the second case, observers initially do not want to ignore the first items, because these are relevant to the task. The representations of the items are therefore actively maintained until the first task is completed. However, by the time this has been accomplished, there is not enough time or resources to visually mark them. In other words, VM never gets a chance to be implemented.

\section{Serial Versus Parallel Implementation}

The present paper indicates how VM is not implemented. It is not applied by a serial attentional scan through old items. The question remains of how it is implemented. We propose that old items are suppressed in parallel. A number of findings in our and other laboratories point toward such a parallel inhibitory mechanism.

A first important indication is the effect of grouping. For instance, Watson (2001; see also Olivers et al., 1999) 
found that VM of moving items is severely impaired when their configuration is broken up by individual items' moving off (and back on) the screen. In contrast, when the items move within a coherent rotating surface, VM remains intact. Watson argued that, at least for motion displays, it may be important for VM to maintain a grouped representation of the old items, so that they can be tracked and inhibited as a single object. Consistent with this, Takeda and Kumada (2002) have recently reported effects of spatial configuration for static displays too. They found that VM was aided when the old items alone formed a bilaterally symmetrical configuration, whereas VM was impeded when the old and the new items together formed a similar configuration. Furthermore, we (Humphreys, Olivers, Heard, \& Linnell, 2002) have found that VM of static displays can be aided if the old items fall within a single outline shape (i.e., a "lasso" drawn around the old set). This grouping by common region was especially beneficial at short preview duration, suggesting that VM may benefit from grouping early in the preview period. Finally, Braithwaite, Humphreys, and Hodsoll (2002), found effects of grouping on the basis of color. Participants were more efficient in searching the new items when the old items all shared the same color than when the old items were of mixed colors (even though these colors were all different from the color of the new items). Related to this, Olivers et al. (1999) found that old moving items could be marked if they had a common color that distinguished them from the new items, even when the motion coherence was broken up by individual items' appearing and disappearing.

These findings strongly suggest that some grouping effects underlie the representations that VM operates on. This makes sense. When grouped into a single representation, the old items will be easier to keep track of and, possibly, require fewer resources to be suppressed. Moreover, grouping may aid further in segregating the old set from the new set. The important implication here is that such groups are likely to be suppressed in parallel, rather than being treated on an item-by-item basis.

A second important indication about how marking occurs is the effect of attentional set. In recent experiments, we presented participants with conditions in which the (second-set) target was a salient feature singleton, relative to the distractors of the new set (Olivers \& Humphreys, 2002a). For instance, the second set could consist of a green left-tilted target bar among red right-tilted distractor bars. Normally, such singleton targets lead to rapid search, independent of the display size (Treisman \& Gelade, 1980). Importantly, however, the singleton target could share its features with the old items (which were green and left-tilted). If a serial inhibition mechanism were employed (e.g., serial inhibition of return), this should not matter. On this view, attention should suppress each old green item in turn, allowing the new green item to pop out of the second display. However, this is not what we found. We found that search for the new green target was often slow, serial, and error prone. We argued that the observers set up an inhibitory set, specifying the features of the to-be-ignored objects. Owing to this set, irrelevant old items were suppressed, and furthermore, this could generalize to new items too, provided they complied with the specified features. Since the new item appeared in a completely new location, this carryover of inhibition to new items is difficult to explain under an inhibition of return account. On the other hand, it is more readily explained by a parallel suppression mechanism operating across the visual field (i.e., operating under the "umbrella" of the inhibitory attentional set).

Finally, evidence for a parallel implementation of VM comes from a series of timing experiments (e.g., Humphreys, Kyllingsbaek, Olivers, Watson, \& Paulson, 2002). In these experiments, both the number of old items and the stimulus onset asynchrony (SOA) between the old and the new set were varied. Consistent with earlier findings (Watson \& Humphreys, 1997), VM became optimal for SOAs of 600-700 msec. Importantly, this was the case regardless of whether four, or eight old items needed to be ignored. This points toward a parallel mechanism involved in the representation of the old items. If visual marking were applied serially (and at a constant rate) to the individual old items, the optimal SOA for four items should have been up to twice as long as that for two items, and the optimal SOA for eight items should have been up to four times longer.

\section{VM and Inhibition of Return}

The present paper demonstrates that VM cannot be explained through inhibition of return as it would operate during search. Such an inhibition-of-return mechanism (if present) would be applied serially from one distractor location to the other, to aid in orienting toward previously uninspected locations. Hence, it would be expected that its effects are measurable for serial searches, but not for parallel searches (Klein, 1988; Müller \& von Muhlenen, 2000; Takeda \& Yagi, 2000). Here, we have shown that VM does not reflect such a mechanism. However, it is possible to conceive of a more flexible inhibitionof-return process that is able to account for the preview benefit in the VM conditions. Instead of being applied on an item-by-item basis to individual locations, inhibition of return would be applied in parallel to multiple locations or configurations of objects (see, e.g., Wright \& Richard, 1996, who found simultaneous inhibition for up to four locations). To account for other effects found with the preview paradigm, such an inhibition-of-return mechanism should also allow for applications to other types of representation, such as color and orientation (see Law, Pratt, \& Abrams, 1995, for color-based inhibition of return; however, see also Taylor \& Klein, 1998; see Braithwaite et al., 2002, and Olivers \& Humphreys, 2002a, for color- and orientation-based VM effects). Moreover, inhibition of return would also have to be (1) a top-down limited capacity attentional process, in order to explain the interference from secondary tasks (Humphreys et al., 
in press; Olivers \& Humphreys, 2002a; Watson \& Humphreys, 1997), (2) independent of eye movements to the old stimuli (Watson \& Humphreys, 1997; viz., Klein \& Taylor, 1994), and (3) dependent on an appropriate attentional set (e.g., Watson \& Humphreys, 2000, failed to find evidence for inhibition of probe dots unless an attentional set for search through the new items was adopted; see also Olivers \& Humphreys, 2002b). If we indeed regard inhibition of return as a top-down attention-demanding inhibitory process that can be flexibly applied to multiple types of representation, it becomes difficult to distinguish VM from inhibition of return, since their definitions are then identical (and indeed, no data will differentiate the two). Although not impossible, we believe that this involves stretching the definition of inhibition of return beyond its original conception as a rather low-level automatic orienting mechanism biasing against previously inspected locations (likely linked to the oculomotor system; Klein \& Taylor, 1994). VM and the original low-level "serial" inhibition of return would then merely be separate instantiations of the omnipresent global inhibition of return (see also Klein, 2000 , for concerns on the overextension of the term inhibition of return).

\section{REFERENCES}

Braithwaite, J. J., Humphreys, G. W., \& Hodsoll, J. (2002). Ignoring color over time: The selective effects of color on preview-based visual search of static items. Manuscript submitted for publication.

Chun, M. M., \& JiAng, Y. (1998). Contextual cueing: Implicit learning and memory of visual context guides spatial attention. Cognitive Psychology, 36, 28-71.

Coull, J. T., \& Nobre, A. C. (1998). Where and when to pay attention: The neural systems for directing attention to spatial locations and to time intervals as revealed by both PET and fMRI. Journal of Neuroscience, 18, 7426-7435.

Folk, C., Remington, R. W., \& Johnston, J. C. (1992). Involuntary covert orienting is contingent on attentional control settings. Journal of Experimental Psychology: Human Perception \& Performance, $\mathbf{1 8}$, 1030-1044.

Gibson, B. S., Li, L., Skow, E., Brown, K., \& Cooke, L. (2000). Searching for one versus two identical targets: When visual search has a memory. Psychological Science, 11, 324-327.

GILCHRIST, I. D., \& HARVEY,M. (2000). Refixation frequency and memory mechanisms in visual search. Current Biology, 10, 1209-1212.

Greene, H. H., \& RaYner, K. (1999). Familiarity and eye movements in visual search. Abstracts of the Psychonomic Society, 4, 88.

Horowitz, T. S., \& Thornton, I. M. (2000). Do we keep track of where we've been or what we've done? Perception, 29(Suppl.), 99b.

Horowitz, T. S., \& Wolfe, J. M. (1998). Visual search has no memory. Nature, 394, 575-577.

Horowitz, T. S., \& Wolfe, J. M. (2001). Search for multiple targets: Remember the targets, forget the search. Perception \& Psychophysics, 63, 272-285.

Humphreys, G. W., Kyllingsbaek, S., Olivers, C. N. L., Watson, D. G., \& PAulson, X. (2002). Parieto-occipital areas involved in efficient filtering in search: A time course analysis of visual marking using behavioral and functional imaging procedures. Manuscript submitted for publication.

Humphreys, G. W., \& Müller, H. J. (1993). Search via recursive rejection (SERR): A connectionist model of visual search. Cognitive Psychology, 25, 43-110.

Humphreys, G. W., Olivers, C. N. L., Heard, J., \& Linnell, K. J. (2002). Just one of the old gang: Grouping by common region affects visual marking. Manuscript in preparation.
Humphreys, G. W., Quinlan, P. T., \& Riddoch, M. J. (1989). Grouping processes in visual search: Effects with single- and combinedfeature targets. Journal of Experimental Psychology: General, 118, 258-279.

Humphreys, G. W., Watson, D. G., \& Jolicceur, P. (in press). Fractionating visual marking: Dual-task decomposition of the marking state by timing and modality. Journal of Experimental Psychology: Human Perception \& Performance.

Kahneman, D., Treisman, A., \& Burkell, J. (1983). The cost of visual filtering. Journal of Experimental Psychology: Human Perception \& Performance, 9, 510-522.

Kingstone, A. (1992). Combining expectancies. Quarterly Journal of Experimental Psychology, 44A, 69-104.

KLEIN, R. [M.] (1988). Inhibitory tagging system facilitates visual search. Nature, 334, 430-431.

KLEIN, R. M. (2000). Inhibition of return. Trends in Cognitive Sciences, 4, 138-147.

Klein, R. M., \& TAYlor, T. L. (1994). Categories of cognitive inhibition with reference to attention. In D. Dagenbach \& T. H. Carr (Eds.), Inhibitory processes in attention, memory, and language (pp. 113150). San Diego: Academic Press.

Kristjansson, A. (2000). In search of remembrance: Evidence for memory in visual search. Psychological Science, 11, 328-332.

Law, M. B., Pratt, J., \& Abrams, R. A. (1995). Color-based inhibition of return. Perception \& Psychophysics, 57, 402-408.

LogAN, G. D. (1988). Toward an instance theory of automatization. Psychological Review, 95, 492-527.

Logan, G. D. (1990). Repetition priming and automaticity: Common underlying mechanisms? Cognitive Psychology, 22, 1-35.

Logan, G. D., TAylor, S. E., \& ETherton, J. L. (1999). Attention and automaticity: Toward a theoretical integration. Psychological Research, 62, 165-181.

MAYloR, E. A., \& Hockey, R. (1985). Inhibitory component of externally controlled covert orienting in visual space. Journal of Experimental Psychology: Human Perception \& Performance, 11, 777787.

Müller, H. J., \& von Muhlenen, A. (2000). Probing distractor inhibition in visual search: Inhibition of return. Journal of Experimental Psychology: Human Perception \& Performance, 26, 1591-1605.

Olivers, C. N. L., \& Humphreys, G. W. (2002a). Visual marking and singleton capture: Fractionating the unitary nature of visual selection. Manuscript submitted for publication.

Olivers, C. N. L., \& Humphreys, G. W. (2002b). Visual marking under attentional blink conditions: More evidence for top-down limited capacity inhibition. Journal of Experimental Psychology: Human Perception \& Performance, 28, 22-42.

Olivers, C. N. L., Watson, D. G., \& Humphreys, G. W. (1999). Visual marking of locations and feature maps: Evidence from withindimension defined conjunctions. Quarterly Journal of Experimental Psychology, 52A, 679-715.

Posner, M. I., \& Cohen, Y. (1984). Components of visual orienting. In H. Bouma \& D. G. Bouwhuis (Eds.), Attention and performance $X$ : Control of language processes (pp. 531-556). Hillsdale, NJ: Erlbaum.

RAuschenberger, R, \& YANTIS, S. (1999). Search asymmetry revisited: A new approach to visual search. Abstracts of the Psychonomic Society, 4, 62.

TAKedA, Y., \& Kumada, T. (2002). Pattern-based visual marking: Evidence for a grouped pattern representation of old items. Manuscript submitted for publication.

TAKedA, Y., \& YAGI, A. (2000). Inhibitory tagging in visual search can be found if search stimuli remain visible. Perception \& Psychophysics, 62, 927-934.

TAY LOR, T. L., \& KLEIN, R. M. (1998). Inhibition of return to color: A replication and nonextension of Law, Pratt, and Abrams (1995). Perception \& Psychophysics, 60, 1452-1456.

Theeuwes, J., Kramer, A. F., \& Atchley, P. (1998). Visual marking of old objects. Psychonomic Bulletin \& Review, 5, 130-134.

Treisman, A., \& Gelade, G. (1980). A feature-integration theory of attention. Cognitive Psychology, 12, 97-136.

Treisman, A., Vieira, A., \& Hayes, A. (1992). Automaticity and preattentive processing. American Journal of Psychology, 105, 341-362. 
Van Selst, M., \& Joliceur, P. (I 994). A solution to the effect of sample size on outlier elimination. Quarterly Journal of Experimental Psychology, 47A, 631-650.

Wang, Q., Cavanagh, P., \& Green, M. (1994). Familiarity and pop-out in visual search. Perception \& Psychophysics, 56, 495-500.

Watson, D. G. (2001). Visual marking in moving displays: Featurebased inhibition is not necessary. Perception \& Psychophysics, 63, 74-84.

Watson, D. G., \& Humphreys, G. W. (1997). Visual marking: Prioritizing selection for new objects by top-down attentional inhibition of old objects. Psychological Review, 104, 90-122.

WAtson, D. G., \& HumphreYs, G. W. (1998). Visual marking of moving objects: A role for top-down feature-based inhibition in selection. Journal of Experimental Psychology: Human Perception \& Performance, 24, 946-962.

Watson, D. G., \& Humphreys, G. W. (2000). Visual marking: Evidence for inhibition using a probe-dot detection paradigm. Perception \& Psychophysics, 62, 471-481.

Wright, R. D., \& RichaRd, C. M. (1996). Inhibition of return at multiple locations in visual space. Canadian Journal of Experimental Psychology, 50, 324-327.

YANTIS, S. (1998). Objects, attention, and perceptual experience. In
R. D. Wright (Ed.), Visual attention (pp. 187-214). Oxford: Oxford University Press.

YANTIS, S., \& JoNidES, J. (1984). Abrupt visual onsets and selective attention: Evidence from visual search. Journal of Experimental Psychology: Human Perception \& Performance, 10, 601-621.

YANTIS, S., \& JonIDES, J. (1990). Abrupt visual onsets and selective attention: Voluntary versus automatic allocation. Journal of Experimental Psychology: Human Perception \& Performance, 16, 121-134.

\section{NOTE}

1. The number of participants excluded because of high error rates may seem unusually high. At least in part, this is probably due to our experimental design. Set 2 trials were contingent upon a correct response to Set 1 . The number of Set 2 datapoints was thus reduced with every Set 1 error, making any Set 2 error have relatively more impact. Making our criterion less stringent would run the risk that some measurements would be based on relatively few datapoints. In Experiment 3, we get around this problem by repeating erroneous trials.

(Manuscript received October 25, 2000; revision accepted for publication July 23, 2001.) 